\title{
Interconnections of Reactive Oxygen Species Homeostasis and Circadian Rhythm in Neurospora crassa
}

\author{
Norbert Gyöngyösi and Krisztina Káldi
}

\begin{abstract}
Significance: Both circadian rhythm and the production of reactive oxygen species (ROS) are fundamental features of aerobic eukaryotic cells. The circadian clock enhances the fitness of organisms by enabling them to anticipate cycling changes in the surroundings. ROS generation in the cell is often altered in response to environmental changes, but oscillations in ROS levels may also reflect endogenous metabolic fluctuations governed by the circadian clock. On the other hand, an effective regulation and timing of antioxidant mechanisms may be crucial in the defense of cellular integrity. Thus, an interaction between the circadian timekeeping machinery and ROS homeostasis or signaling in both directions may be of advantage at all phylogenetic levels. Recent Advances: The Frequency-White Collar-1 and White Collar-2 oscillator (FWO) of the filamentous fungus Neurospora crassa is well characterized at the molecular level. Several members of the ROS homeostasis were found to be controlled by the circadian clock, and ROS levels display circadian rhythm in Neurospora. On the other hand, multiple data indicate that ROS affect the molecular oscillator. Critical Issues: Increasing evidence suggests the interplay between ROS homeostasis and oscillators that may be partially or fully independent of the FWO. In addition, ROS may be part of a complex cellular network synchronizing non-transcriptional oscillators with timekeeping machineries based on the classical transcription-translation feedback mechanism. Future Directions: Further investigations are needed to clarify how the different layers of the bidirectional interactions between ROS homeostasis and circadian regulation are interconnected. Antioxid. Redox Signal. 20, 3007-3023.
\end{abstract}

\section{Introduction}

$\mathrm{C}$ IRCADIAN TIMEKEEPING ALlows organisms to align their physiology with regular upcoming events in their surroundings that vary with a daily cycle. The basic mechanisms enabling endogenous time measuring seem to be highly conserved among higher and lower eukaryotes. The filamentous fungus Neurospora crassa has proven to be extremely useful for dissecting the basic organization of the circadian clock. The Neurospora clock is an attractive model that allows all layers of molecular investigations to be performed, from genetic approaches to investigations of gene expression and molecular interactions.

Besides reflecting physiological fluctuations of the metabolic activity, cellular reactive oxygen species (ROS) levels are highly elevated under oxidative stress situations. Although ROS have long been considered deleterious byproducts of metabolism, increasing evidence suggests that they play important messenger roles in the regulation of many cell functions $(31,50,85,116,149)$. The fundamental function of ROS was proposed in Neurospora more than 20 years ago, as elevation of ROS production was found to be a prerequisite of the morphogenetic transitions of the fungus (62). In the meantime many details of ROS-regulated cellular functions have been described and novel ROS-related signaling pathways have been identified. Moreover, several data indicate an interrelationship between ROS signaling and the circadian rhythm in Neurospora, that is, ROS levels oscillate in a circadian manner, and vice versa, ROS homeostasis is involved in the control of the circadian rhythm $(16,61,180,181)$. Very recently, circadian oxidation cycles of peroxiredoxin were shown in multiple organisms including Neurospora (47). These data suggest that, in addition to the well-described transcriptiontranslation feedback loops (TTFLs), and most probably interacting with them, non-transcriptional oscillations could be common mechanisms of circadian timekeeping.

Department of Physiology, Semmelweis University, Budapest, Hungary. 
This review summarizes our knowledge of both the ROS-generating systems and the antioxidant mechanisms of Neurospora. In addition, we introduce the molecular organization and environmental control of the Frequency (FRQ)based oscillator and discuss rhythms that are independent of the classic TTFL of the fungus. Finally, we focus on the oscillations of ROS levels and the data suggesting that the cellular redox state may feedback on the circadian clock.

\section{Generation of Circadian Rhythm in Neurospora crassa}

\section{Circadian rhythm in Neurospora}

Since the pioneer work of Pittendrigh et al. (125) the Neurospora clock belongs to the most extensively examined timekeeping machineries. A variety of Neurospora strains helped to understand the basic mechanisms of the operation of circadian rhythm. Primary observations in Neurospora often provided the initial stimulus for targeted molecular investigations in higher organisms.

Under certain conditions the formation of asexual spores (macroconidia) is driven by the internal clock in Neurospora. The race tube assay has proved to be the most useful experimental tool for simple monitorization of this rhythmic process $(8,131)$. Race tubes are hollow glass tubes containing solid agar medium (Fig. 1A). This medium is inoculated with conidia at one end of the tube, so that the culture will grow across the agar surface. Typically, after 1 day of growth single cells of the cultures are synchronized by a light-dark transfer or temperature shift. This is then followed by incubation either under constant conditions or at an entraining cycle (lightdark or temperature cycle) for several days. During this period, once a day a developmental switch occurs leading to the formation of a conidial band. Since the growth rate is more or less constant throughout the day, by marking the growth front each day, one can construct a time scale. Conidial density will be determined along the tube and density changes will be analyzed as a function of time allowing determination of period length, phase, or amplitude of the conidiation rhythm. By using a similar method, as described for the race tubes, rhythmic spore formation can also be analyzed when Neurospora cultures grow on plates (16).

This pattern of spore formation, also called banding, is often masked in wt strains, because an elevation of carbon dioxide $\left(\mathrm{CO}_{2}\right)$ levels that is typical in race tubes results in suppression of conidiation $(8,103,135)$. To overcome this problem, series of mutants have been isolated that allowed better visualization of rhythmic development $(8,134,152)$. The band $(b d)$ strain that carries a mutation in the ras-1 gene (12) displays very robust conidiation rhythm in race tubes. For this reason, most strains used in chronobiological experiments have been generated in a $b d$ background. Conidiation rhythm in $w t$ can be induced by elevation of ROS levels, that is, addition of hydrogen peroxide $\left(\mathrm{H}_{2} \mathrm{O}_{2}\right)$ to the medium or treatment of the cells with the ROS generator menadione (Fig. 1B) $(12,61)$. As an alternative method, the inverted race tube assay has been developed that allows a better visualization of rhythmic banding by preventing the accumulation of $\mathrm{CO}_{2}$ in the tubes (150).

Recently, the adaptation of the luciferase reporter assay for use in Neurospora allowed the high-throughput analysis of the promoter activity of clock and clock-controlled genes (ccgs) $(57,111)$.

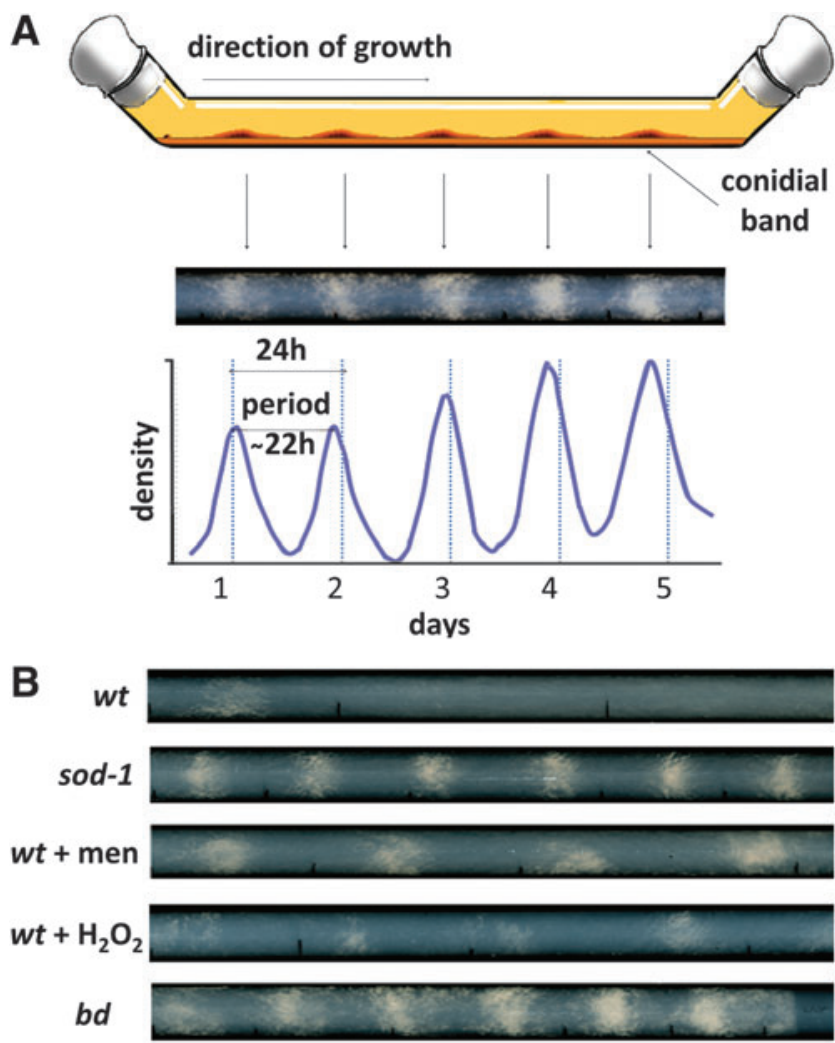

FIG. 1. Principles of the race-tube assay. (A) Upper panel: The glass tube is filled with solid medium that is inoculated with Neurospora. Following synchronization (e.g., light-dark transfer) the race tube is incubated in constant darkness for several days. The growth front is marked every day and mark time is recorded. Middle panel: Image of a race tube culture of the $b d$ strain. Black lines are growth front marks. Lower panel: Densitometrical analysis of the image of the $b d$ culture as a function of time. Dashed lines indicate every $24 \mathrm{~h}$. The endogenous period of the strain is clearly shorter than $24 \mathrm{~h}$. Analysis of the race tube was performed with the ChronOSX 1.0.7 software (T. Roenneberg, LMU Munich). The figure was adapted from Baker et al. (8). (B) Both the $b d$ mutation and elevated ROS levels support conidial banding. Race tubes were inoculated with the indicated strains and following synchronization incubated at $25^{\circ} \mathrm{C}$ in constant darkness. Where indicated, menadione (men, $50 \mu \mathrm{M}$ ) or $\mathrm{H}_{2} \mathrm{O}_{2}$ $(2 \mathrm{mM})$ was added to the medium. $b d$, band; $\mathrm{H}_{2} \mathrm{O}_{2}$, hydrogen peroxide; ROS, reactive oxygen species; sod-1, superoxidedismutase-1 mutant. To see this illustration in color, the reader is referred to the web version of this article at www .liebertpub.com/ars

\section{The molecular clock of Neurospora}

In most cases the rhythmic phenotype of Neurospora is dependent on the oscillating expression of the negative clock component FRQ. Rhythmic expression of frq is governed by the positive factor White Collar Complex (WCC) consisting of the GATA-family transcription factors White Collar-1 (WC-1) and White Collar-2 (WC-2). Based on these main components, this machinery is also referred to as Frequency-White Collar-1 and White Collar-2 oscillator (FWO; FRQ-WC-1-WC-2 oscillator). Since both the positive and the negative components of the clock are regulated by phosphorylation, several kinases and phosphatases are also important constituents of the 
central oscillator. At least five kinases play a role in the phosphorylation of FRQ, that is, casein kinase-1a and casein kinase-2 (CK-1a and CK-2), Period-4 (PRD-4), $\mathrm{Ca}^{2+} /$ calmodulin-dependent protein kinase-1 (CAMK-1), and protein kinase $\mathrm{A}(58,72,106,126,176,177)$. The two major phosphatases, protein phosphatase 1 and $2 \mathrm{~A}$ and the protein phosphatase 4 (PP4) have been described as regulators of FRQ phosphorylation $(19,178)$. Phosphorylation of the WCC is dependent on CK-1a and CK-2 and the protein phosphatase 2A (PP2A) and PP4 (19, 66, 136, 137). Two chromatin remodeling enzymes CLOCKSWITCH and chromodomain helicase DNA-binding that directly control frq transcription are also important factors of the FWO $(12 a, 13)$.
Both FRQ and the WC proteins possess constant interaction partners. FRQ forms a complex (FRQ-FRQ-interacting RNA helicase [FRH] complex, FFC) with the FRH that stabilizes it during the whole circadian cycle $(26,60)$. WC- 1 is only stable when it interacts with WC-2, and WC-1 is the limiting component of the WCC (27). The heterodimerization of the WC-proteins is dependent on the interaction via their PerArnt-Sim (PAS) domains $(9,27,95,158)$.

Figure 2 shows the most important stages of the FWObased clock cycle. In the late subjective night (segment of the free-run period corresponding to the dark segment of a light/ dark [LD] cycle) the WCC starts inducing frq transcription. Following the increase of frq RNA levels, FRQ protein is

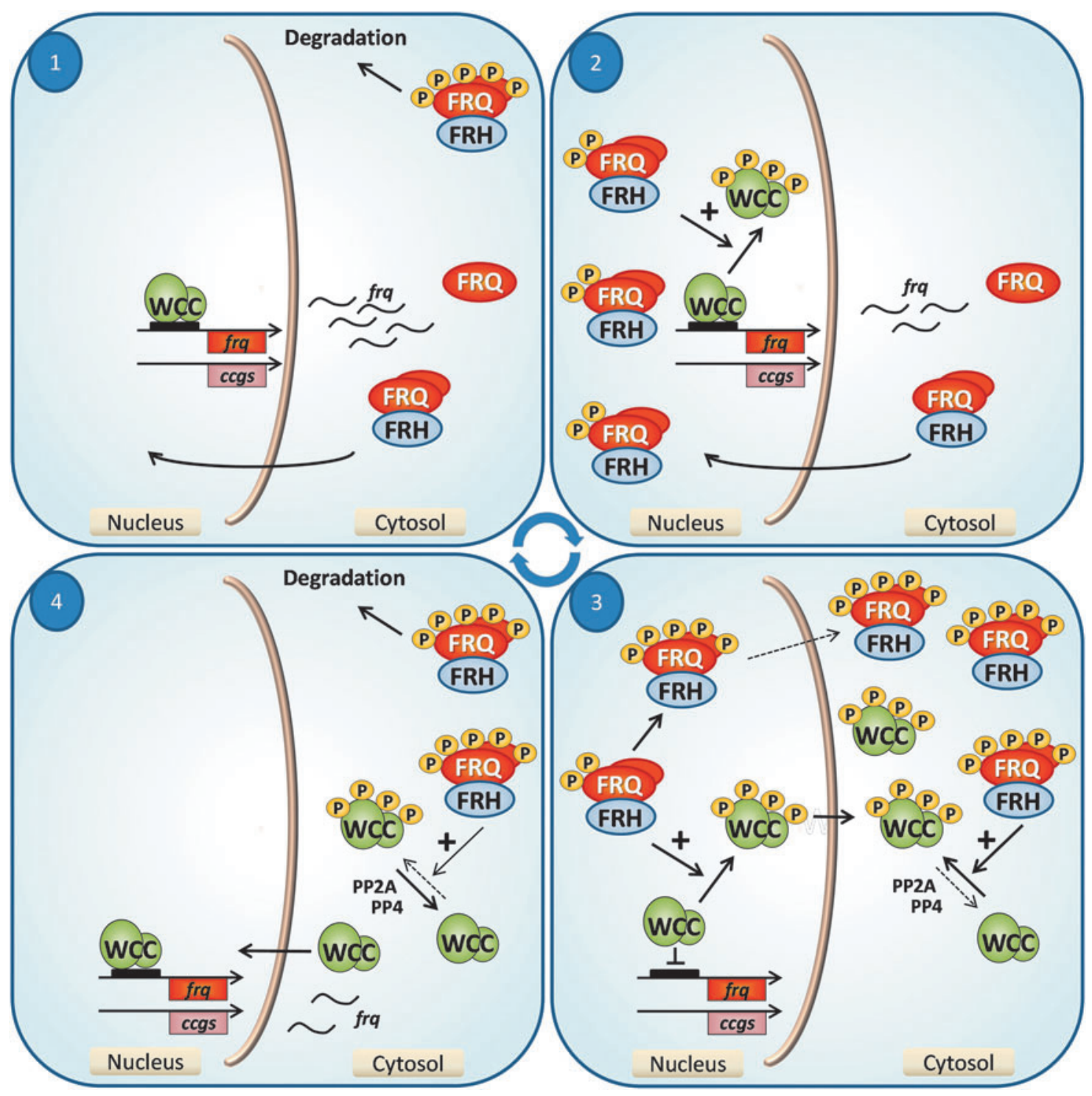

FIG. 2. Cycling molecular events in the FWO. Stage 1: Beginning in the late night, the WCC effectively supports transcription of frequency (frq). FRQ protein is synthesized with a 4-6-h delay and in complex with the FRH enters the nucleus. Stage 2: By the mid subjective day, FRQ is accumulated in the nucleus, where it promotes phosphorylation of the WCC and, as a consequence, frq transcription slows down. Stage 3: In the subjective evening, frq transcription is minimal. FRQ becomes hyperphosphorylated and dominantly localizes to the cytosol, where it supports accumulation of the inactive WCC. Stage 4: During the night hyperphosphorylated FRQ is degraded. Consequently, dephosphorylation of the WCC dominates over phosphorylation and the active form of the complex enters the nucleus. $c c g$, clock-controlled gene; FRH, Frequency-interacting RNA helicase; FRQ, Frequency; FWO, Frequency-White Collar-1 and -2 oscillator; P, phosphate; PP, protein phophatase; WCC, White Collar Complex. To see this illustration in color, the reader is referred to the web version of this article at www.liebertpub.com/ars 
synthesized with a certain delay, that is, FRQ levels peak 4-6 h later than RNA levels $(4,52,108)$. FRQ forms homodimers (28) and associates with FRH $(26,60)$. The FFC then translocates into the nucleus and promotes inactivation of the WCC. However, a simple complex formation between the positive and the negative components is not sufficient for the negative feedback; even when FRQ levels peak, the WCC is present in large excess over nuclear FRQ, thus the majority of the WCC cannot be in complex with FFC (137). Instead, FFC inactivates the WCC by supporting its phosphorylation by CK-1a and CK-2 $(66,137)$. During this period, FRQ also becomes sequentially phosphorylated at multiple sites. Phosphorylation of FRQ on the one hand interferes with its nuclear import, leading to its accumulation in the cytosol. On the other hand, phosphorylation - especially that of the N-terminal domain of FRQ by CK-1a-changes the stability of the protein, most probably by initiating a conformational change that leads to the exposition of degradation signals $(127,138)$. FRQ then interacts with its ubiquitin ligase F-box WD-40 repeatcontaining protein-1 and becomes degraded by the proteosome pathway (68). As a consequence, phosphorylation of the WCC is not further supported. Instead, dephosphorylation dependent on both PP4 and PP2A promotes nuclear entry of the active WCC and thus a new cycle can start $(19,136)$. As a result of the precise temporal organization of the above described events, the transcriptional activity of the WCC peaks in the early subjective morning leading to the accumulation of FRQ during the subjective day, whereas repression of the WCC reaches its maximum in the late evening.

The negative feedback loop is interconnected with two positive feedback loops. One of these is an autoregulatory loop, in which the WCC supports its own expression at the transcriptional level $(76,117)$. In the other loop, FRQ positively controls WCC levels by a mechanism that is most probably tightly coupled to the negative feedback. This mechanism is based on the fact that stability of the WCC is highly dependent on its activity; DNA binding triggers the degradation of the WCC, a phenomenon also observed for other transcription factors $(80,136)$. However, FRQ by promoting phosphorylation of the WCC inhibits both DNA binding and nuclear import of the positive factor. As a consequence, especially in later phases of the cycle when FRQ is hyperphosphorylated and dominantly localized to the cytosol, WCC also accumulates at high levels in the cytosol.

\section{Light entrainment of the Neurospora clock}

Light input of the Neurospora clock is mediated by the WCC. All blue-light responses are dependent on WC-1, the primary blue-light receptor of Neurospora (10). Light promptly activates the WCC that induces transcription of hundreds of genes containing light-responsive elements $(10,25,44,45,89$, 148). Light activation of the WCC is mediated by the lightoxygen-voltage-sensing domain (LOV domain, also called PAS-A domain) of WC-1. The LOV domain is associated with flavine adenine dinucleotide that, in response to light, covalently binds to a cysteine residue of WC-1 leading to the formation of a stable light-activated state $(29,67)$. Light activation of the WCC is accompanied by two additional events, that is, hyperphosphorylation of the complex and formation of homodimers, a process mediated by the LOV domains (105). Light-dependent phosphorylation of the WCC is, at least partially, mediated by protein kinase $C(51)$.

When Neurospora is transferred from light to dark, WC-1 is not able to be reactivated by light for several hours, suggesting that the photocycle of WC-1 is relatively slow (69). Nonetheless, the mechanism of the regeneration of photoactivated WCC is still not clear.

Following irradiation, frq levels immediately increase by peaking within about $5 \mathrm{~min}$. However, the extent of this light response is gated by the circadian clock, so that similar light signals are most effective in the subjective morning, when the light phase would start in natural photoperiods $(70,108)$. Similarly, how a light pulse changes the phase of the oscillator depends on the circadian time. When light is administered in the late subjective night, the relatively early increase in $\mathrm{frq}$ levels results in an advance of the clock. Conversely, when a light pulse is received around the subjective dusk when frq levels are already decreasing, light-induced elevation of frq expression sets the clock back to earlier times, that is, the oscillator is delayed $(8,34)$.

Light entrainment of the clock is modulated by the secondary photoreceptor VIVID (VVD) (70). VVD is a small protein consisting of a single LOV-domain similar to that of WC-1 $(144,184)$. Expression of VVD is dependent on the activation of the WCC by light, that is, following a light-dark transfer VVD levels gradually decrease $(70,105)$. VVD acts as a repressor of light responses by disrupting the WCC dimers, and thus plays a crucial role in the photoadaptation of $\mathrm{Neu}$ rospora $(23,74,105)$. While in wt Neurospora elevation of lightinduced gene expression is transient and expression levels stabilize at relatively low levels within $1-2 \mathrm{~h}$, in vvd-deficient strains enhanced light responses are detected for several hours $(143,144,146)$. As a consequence, vvd mutants are less sensitive to changes of light intensity $(56,105,144)$.

In photocycles, the action of FRQ and VVD is similar, that is, both support inactivation and accumulation of the WCC. WC-1 shows a more rapid turnover in light than in dark; on the one hand, photoactivated and hyperphosphorylated WC1 becomes rapidly degraded $(88,158)$; on the other hand, light induction of $w c-1$ ensures replenishment of the WC-1 pool. These mechanisms and the action of both VVD and FRQ together ensure that WC-1 levels are stable in constant light. While FRQ is present in both light and dark, expression of VVD depends on light and its effect is finely controlled by light intensity (105).

Although VVD is not essential for clock function, in photocycles the phase of the oscillator is dependent on VVD (70). VVD allows the oscillator to run during the daytime and take phase cues from dusk (48). In addition, VVD contributes to the robustness of clock functioning. In the dark period, VVD functions as a molecular memory by transferring information from the preceding light period and thus protecting the clock during the night from disturbing light signals of relatively low intensity (e.g., moonlight) (105).

In the light period of a LD cycle frq levels are high, whereas they rapidly drop following the LD transition $(61,159)$. Then, in the second half of the dark period frq levels rise again, reflecting the reactivation of the WCC. However, the exact molecular mechanism of clock functioning under entrained conditions is still not entirely clear, and the simple transcriptional-translational feedback model is not sufficient to explain all molecular events. Tan et al. (159) showed that transcription 
and translation of FRQ are dissociated in photocycles (up to a delay of $6 \mathrm{~h}$ ) and the delay depends on the light portion of the cycle. These interesting data suggest that additional posttranscriptional mechanisms play an important role in clock regulation under entrained conditions.

\section{Temperature as an input of the circadian clock in Neurospora}

Although the length of the circadian period is temperaturecompensated, temperature shifts reset the phase of the oscillator. Temperature primarily affects FRQ levels; at higher temperature FRQ levels oscillate around higher mean levels (96). Since the average expression levels of frq and the amplitude of frq rhythm are similar at low and high temperatures, abundance of FRQ is controlled at the posttranscriptional level. More specifically, the open reading frame of frq encodes a large and a short isoform of FRQ (long Frequency [IFRQ] and short Frequency, respectively). Relative abundances of these isoforms are controlled by temperature-sensitive alternative splicing. At low temperature (e.g., $15^{\circ} \mathrm{C}$ ) similar levels of both isoforms can be detected, whereas at higher temperatures (over $20^{\circ} \mathrm{C}$ ) the $1 F R Q$ dominates $(32,42)$. The translation of IFRQ is especially thermosensitive and thus determines the overall level of FRQ at different ambient temperatures.

The mechanism of clock resetting in response to temperature shifts is also based on the fact that mean levels of FRQ are strongly dependent on the temperature. Following a shift to a higher temperature, the relatively low levels of FRQ are not sufficient to efficiently repress the WCC, and the clock will be reset to a phase when FRQ expression is relatively low (subjective dawn). Conversely, when Neurospora is shifted to a lower temperature, the new phase corresponds to dusk (97).

However, the exact molecular mechanism underlying the temperature compensation of the circadian period is not fully understood. Nevertheless, the compensation profile is dependent on the phosphorylation of FRQ by CK- 2 and, also the differential expression of the FRQ isoforms appears to play a fine tuning role $(41,106)$. In addition, temperature compensation of the circadian phase is dependent on VVD (73).

\section{Output of the Neurospora clock}

The output pathways of the circadian clock mediate time information from the oscillator to distinct cellular functions and thereby generate the overt physiological rhythm. During the last decade technical development has greatly accelerated the identification of $\operatorname{ccgs}$ and helped to uncover molecular mechanisms by which the oscillator is able to differentially control specific subsets of genes. Bell-Pedersen and her coworkers used microarrays representing more than 1400 genes and found rhythmic expression in 145 cases, suggesting that, similarly to other organisms, also in Neurospora about $10 \%$ of the genome is controlled by the circadian clock (33). The proteins encoded by the identified genes represent a wide range of cellular processes, including signal transduction, development, metabolism, and stress reactions. In case of three genes rhythmic expression was demonstrated even in a frq-deficient strain, indicating the participation of a FRQ-less oscillator (FLO, see later) in the expression control. Recently, a genome-wide analysis searching for targets of the lightactivated WCC identified hundreds of possible binding sites including genes of several transcription factors controlling important regulatory pathways (148). Although the characterization of these factors for circadian control is still not complete, some of them have already been revealed as important outputs of the clock. An attractive example is conidial separation 1 (CSP-1), a global circadian repressor that modulates expression of ca. 800 genes in Neurospora (132). Many of these genes show rhythmic expression by peaking in the evening and are involved in the regulation of metabolism. CSP-1 mediates a glucose-dependent feedback on $w c-1$ expression and thus contributes to metabolic compensation of the circadian period (133).

In addition, a genetic screen uncovered the circadian regulation of the mitogen-activated protein kinase (MAPK) pathway, a signaling route playing a role in the control of osmotic stress, sexual development, conidial integrity, and fungicide sensitivity $(168,169)$. Expression of the MAPK kinase kinase and the histidyl-phosphotransferase, two important regulators of this pathway have been shown to oscillate at the transcriptional level (84).

As the above data indicate, although the WCC is a direct activator of a series of output genes, many effects of the core clock on basic cellular functions are mediated by the WCC in an indirect way via the control of important regulatory networks.

\section{FRQ-less rhythms in Neurospora}

Under special conditions rhythmic phenotype can be detected even in strains carrying mutations of one or more core components of the FWO. These rhythms display periods in the circadian range and include conidiation $(3,46,59,81,82$, $104,107)$ and molecular or biochemical rhythms (30, 33, 36, 47, 128). However, many of these rhythms are not temperaturecompensated and thus do not fulfill all criteria of a circadian rhythm. They are often dependent on supplementation of the growth medium with factors such as farnesol, geraniol, caffeine, or the ROS generator menadione $(16,59,82)$, and / or are detected in specific single and double mutants $(82,101$, 142, 181).

Compared to the FWO, little is known about the molecular nature of these FLOs. However, two mutations have been shown to severely affect FRQ-less rhythms: prd-1 and prd-2 (91). Although the products of these genes have not been identified yet, they are possible candidates for components of the FLO. Very recently, a mutagenesis screen identified the UV90 mutation that probably affects a factor required for a functional FLO (92).

\section{ROS Homeostasis in Neurospora crassa}

\section{Source of ROS in Neurospora}

ROS represent chemically reactive molecules or free radicals (chemical species with one unpaired electron) containing oxygen (Fig. 3). This group includes molecules formed by excitation of $\mathrm{O}_{2}$ (singlet oxygen, ${ }^{1} \mathrm{O}_{2}$; ozone, $\mathrm{O}_{3}$ ), superoxide anion radical $\left(\mathrm{O}_{2}{ }^{--}\right), \mathrm{H}_{2} \mathrm{O}_{2}$, hydroxyl radical $(\mathrm{OH} \bullet)$, and oxygen radicals or peroxides with other elements (nitric oxide, $\mathrm{NO} \bullet$; peroxynitrite, $\mathrm{ONOO}-$ ) or compounds (lipoperoxides).

Generally, one of the main sources of ROS is metabolism (5, $53,147)$. As in other organisms, in fungi, mitochondrial respiration generates $\mathrm{O}_{2}{ }^{\bullet-}$ due to the incomplete reduction of 


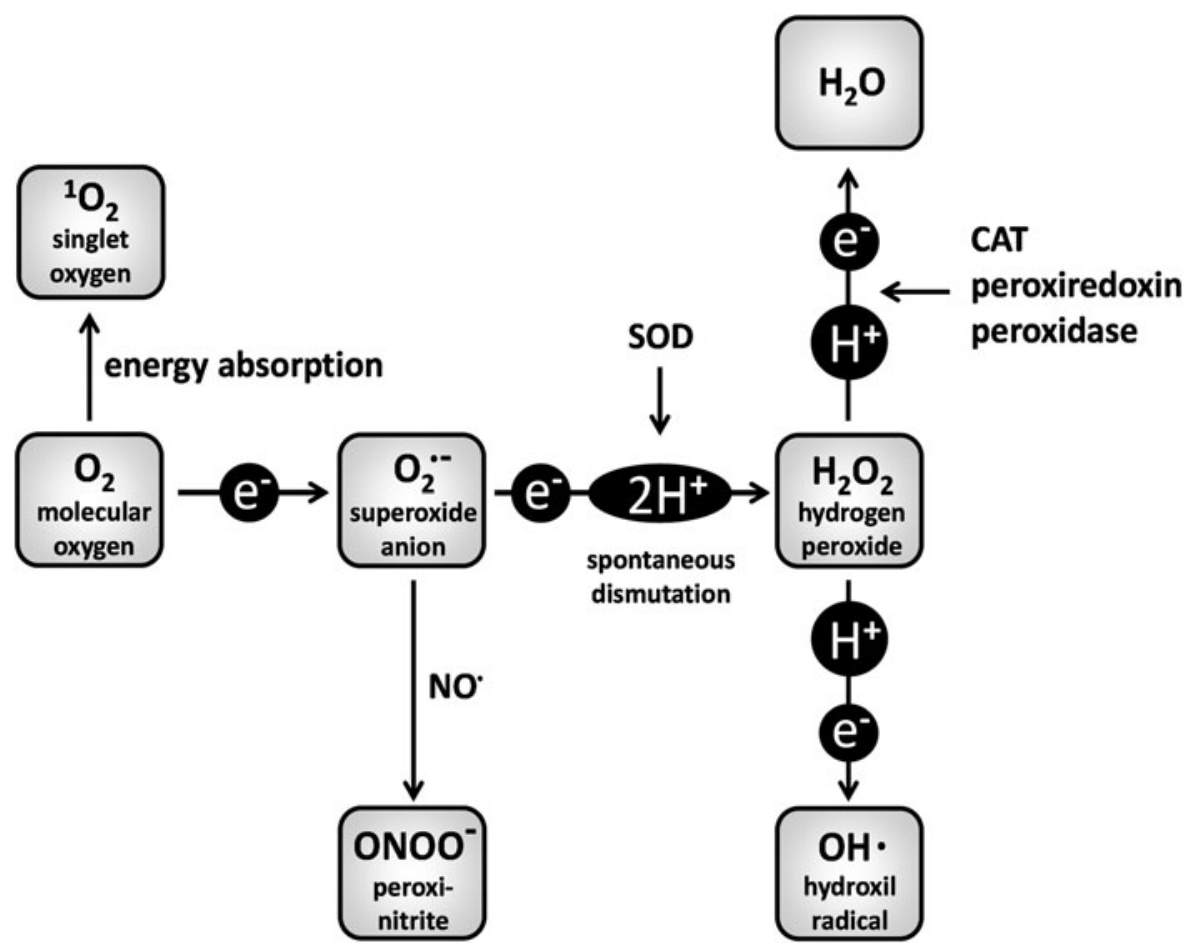

FIG. 3. Formation of ROS in the cell.

oxygen $(18,122,130)$. Besides, ROS are accumulated as intermediate products in reactions involving oxidases such as xanthine oxidase, or dioxygenases such as microsomal monooxygenases and lipoxygenases. In addition, ROS can be produced from thiols, flavins, quinones, and catecholamines by autoxidation during metabolic processes, and reduction of xenobiotics is also considered as a source of ROS. Light also increases the intracellular concentration of ROS $(86,93$, $100,121,180)$.

Cellular $\mathrm{O}_{2}{ }^{\bullet-}$ is actively generated by nicotinamide adenine dinucleotide phosphate (NADPH) oxidases (NOXes). These enzymes use NADPH and $\mathrm{O}_{2}$ to produce $\mathrm{O}_{2}{ }^{\bullet-}$. Among them, NOX-1 and NOX-2 have been so far characterized in N. crassa (17). Fungal NOXes and their role in development were recently overviewed in different works $(1,2,157)$.

\section{Antioxidant system in Neurospora crassa}

The antioxidant system in fungi was recently reviewed in detail $(14,53)$. In the following section, relevant data provided from Neurospora crassa are summarized (Fig. 3).

Superoxide-dismutases (SODs) catalyze the dismutation of $\mathrm{O}_{2}{ }^{\bullet-}$ into $\mathrm{H}_{2} \mathrm{O}_{2}$ and $\mathrm{O}_{2}$. Database searches of the Neurospora genome revealed the existence of two genes encoding $\mathrm{Cu} / \mathrm{Zn}$ SODs and two additional ones encoding Mn-SODs (156). Only two of the putative SODs have been thoroughly characterized so far $(20,21,71)$. The cyanide-sensitive and $\mathrm{Cu} / \mathrm{Zn}$ containing SOD-1 represents most of the SOD activity in cell extracts and is localized in both the cytosol and the intermembrane space of mitochondria. The cyanide-insensitive $\mathrm{Mn} / \mathrm{Zn}$-containing SOD-2 was detected only in the mitochondrial matrix. Nevertheless, extracellular SOD activity was also described in Neurospora $(112,113)$. In both the conidia and mycelia of the sod-1 ${ }^{\text {rip }}$ mutant an upregulation of SOD-2 activity was found suggesting the existence of a compensa- tory mechanism (20). Beside an increased spontaneous mutation rate, sod-1 mutants show reduced growth rate and conidial survival and are more sensitive to the $\mathrm{O}_{2}{ }^{\bullet-}$ generating paraquat and elevated $\mathrm{O}_{2}$ levels. Increased sensitivity of the growth rate to the ROS generator menadione was also detected in sod-1 ${ }^{\text {rip }}$ (author's unpublished observation).

Catalases (CATs) decompose $\mathrm{H}_{2} \mathrm{O}_{2}$ to water and molecular oxygen. Fungal CATs were reviewed recently (64). Up to now, four CATs have been identified in Neurospora. CAT-1 and CAT-3 represent typical large monofunctional CATs (38-40, $43,109)$, whereas CAT-2 is a member of the CAT-peroxidase family. CAT-4 is a small-subunit monofunctional CAT (124, 140). Investigation of the three CAT isoforms CAT-1, CAT-2, and CAT-3 showed that these proteins are not associated with any intracellular compartment, that is, they are located in the cytosol. In addition, CAT- 1 and CAT-3 were found to be secreted, and, at least partially, bound to the cell wall $(109,110$, 140). Although CAT-4 is not at all or only very weakly expressed under conditions tested so far, overexpressed CAT-4 was also localized to the cytosol. Interestingly, Neurospora crassa seems to lack CAT-containing peroxisomes (140). As it was shown in a cat-3 ${ }^{\text {rip }}$ strain, lack of CAT-3 is not compensated for by any other CATs or $\mathrm{H}_{2} \mathrm{O}_{2}$-disposing enzymes (110). CATs are differentially regulated under stress conditions. This led to the hypothesis that CAT-3 is mainly responsible for the rapid compensation of stress, whereas CAT-1 activity is augmented in response to severe stress, that is, when resistant cell structures such as conidia are formed (109). CAT-2 activity was found to be related to conditions when the vacuolization of hyphae is extensive (124).

Carotenoids are known for their antioxidant properties (167). $\beta$-Carotene, neurosporaxanthin, and astaxanthin are the major carotenoids in fungi. Oxygen, ROS, and light (which is known to produce ROS) have been shown to stimulate carotenogenesis in Neurospora $(55,75,179)$. In accordance with 
this, the carotene content is elevated in cat- $3^{\text {rip }}$ compared to $w t$ either in dark or light (110). ROS, especially ${ }^{1} \mathrm{O}_{2}$, were found to oxidize CAT-1 (99). CAT-1 oxidation, degradation [degradation of oxidized proteins is generally enhanced $(35,37,98)]$, and synthesis are more apparent in carotenoid mutants during germination, also showing that the lack of carotenoids increases oxidative stress in Neurospora (98).

Peroxiredoxins are ubiquitous antioxidant enzymes catalizing the reduction of peroxides (ROOH) to alcohols (129). $\mathrm{H}_{2} \mathrm{O}_{2}, \mathrm{ONOO}-$, and a wide range of organic hydroperoxides are detoxified by their activity $(14,53,172)$. The relationship of the peroxiredoxin system and the circadian rhythm was investigated in Neurospora crassa (47) and is discussed later in this review.

Glutathione exists in both reduced (GSH) and oxidized states. GSH is able to reduce ROS and then to react with another glutathione molecule to form glutathione-disufide (oxidized glutathione [GSSG]). Characteristic changes in the GSH/GSSG ratio were described in Neurospora during differentiation and aging (49).
ROS homeostasis progressively changes during cell differentiation

A scheme representing important stages of the Neurospora life cycle is shown in Figure 4. At different stages of the ontogeny changes in the redox balance and ROS levels have been reported that coincide with alterations in oxidation of proteins, SOD, and CAT activities; levels of extractable SH-groups; and the GSH/ GSSG ratio $(2,15,22,49,54,62,63,99,109,112,124,145)$.

Contribution of NOXes in the development is common in the kingdom of fungi $(1,157)$. In Neurospora, NOX-1 seems to be essential for the development and maturation of perithecia (the perithecium is the female sexual reproductive organ, or fruitbody, which contains the ascospores produced by meiosis) $(102,183)$. Although ascospores of the nox-2 mutant show wild-type appearance, they fail to germinate, indicating that NOX-2 is required for sexual spore function. Deletion of nox-1 results in reduced formation of aerial hyphae and conidia, and a lower growth rate of mycelia. In contrast, in the nox-2 strain the asexual development was not affected. The activity

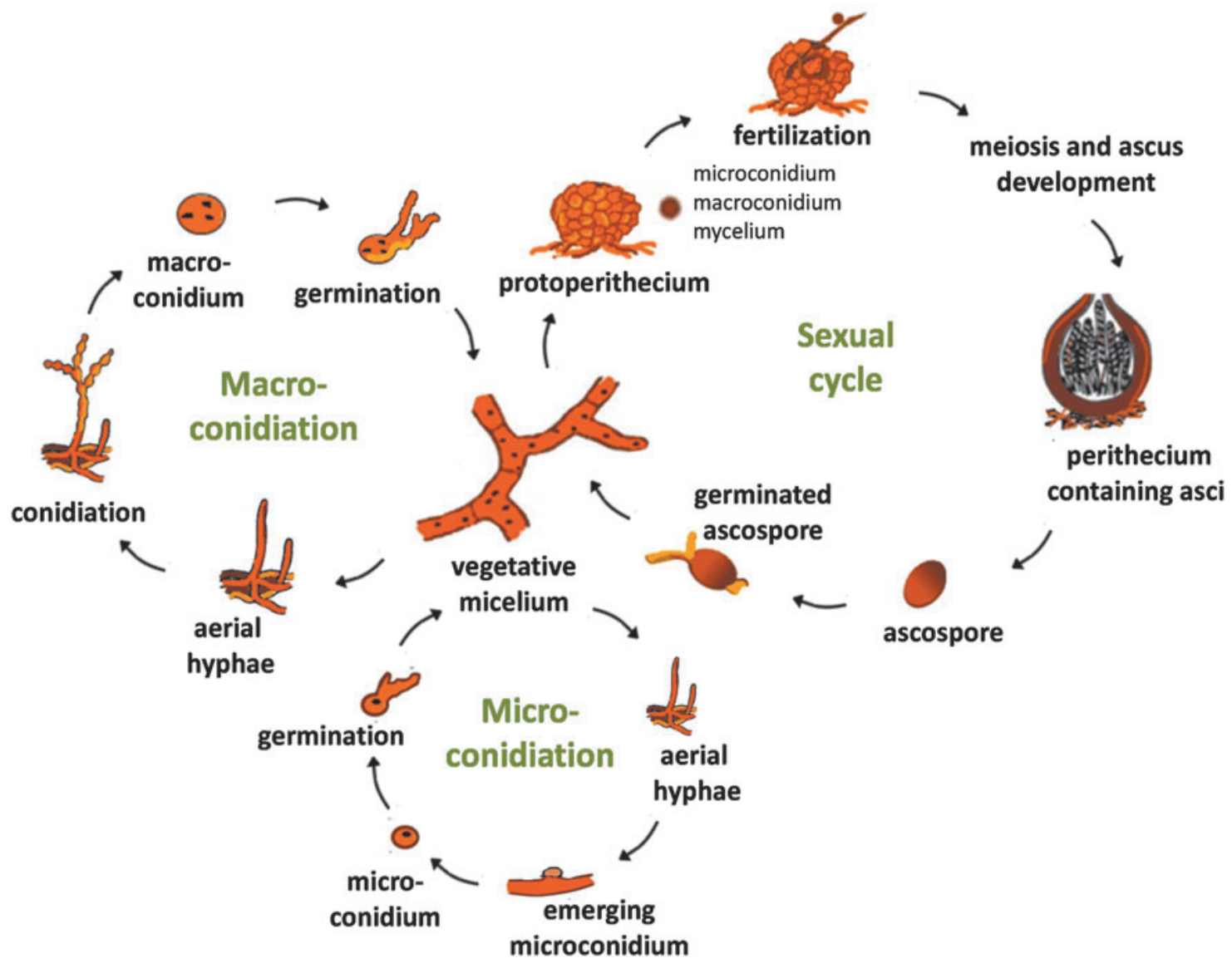

FIG. 4. Life cycle of Neurospora crassa. The fungus spends most of its life cycle as a haploid organism. A haploid asexual spore (micro- or macroconidium) germinates and builds up a vegetative mycelium constituted of hyphae. Hyphae have incomplete cross walls, thus the colony grows as a multinucleate syncytium. Vegetative mycelia produce two types of vegetative spores or conidia from aerial hyphae, the multinucleate macroconidia and the uninucleate microconidia. Both types of vegetative spores are able to disperse and repeat the asexual cycle. In the sexual phase, colonies of opposite mating type interact. Protoperithecia are unfertilized female reproductive organs that can be fertilized by male elements (microconidium, macroconidium or hyphae) of the opposite mating type. After fusion of nuclei, each diploid nucleus undergoes meiosis and mitosis producing haploid ascospores inside the fruiting bodies called perithecia. Ascospores from asci germinate and produce mycelia forming a new colony. Based on Springer (151). To see this illustration in color, the reader is referred to the web version of this article at www.liebertpub.com/ars 
of both NOX-1 and NOX-2 is regulated by the p67phox ortholog NADPH oxidases regulator (NOXs regulator). It is noteworthy that although the lack of CAT-3 causes an increase in asexual growth, in the double mutant nox-1, cat-3 asexual development was similarly reduced to the nox-1 strain, suggesting that NOX-1 activity is required for enhanced development in the cat-3 strain (17).

CATs also participate in the organization of development in Neurospora. They are regulated differentially during different growth stages $(22,109,124)$. Mutants lacking the cat-1 or cat-3 gene show a temperature-dependent increase in the branch density of the growing hyphae, whereas the branch density of $w t$ is independent of the temperature (171). Involvement of CAT-3 in the morphogenesis of hyphae is also supported by results showing that the deletion of cat-3 rescues the morphological change of the hyphae in a mutant lacking nucleoside diphosphate kinase-1 (87). Lack of the cat-1 gene also causes a marked reduction in the conidial germination rate and viability (170). A hyperoxidant state was found to be present during the germination that leads to the oxidation and degradation of CAT-1, followed by de novo synthesis and thus accumulation of cat-1 mRNA (99).

Based on its easily detectable rhythm, the production of asexual spores is extensively studied in the field of circadian research. During the conidiation process, the activity of the actors of ROS homeostasis progressively changes parallel with ROS levels, and certain phases of conidia formation are inhibited by antioxidant treatment (63). When mycelia grown in liquid culture are transferred to air, the hyphae first adhere to each other followed by the development of aerial hyphae. Later, the tips of the aerial hyphae start forming conidia (162). At the start of each morphogenetic transition, a hyperoxidant state was demonstrated by different methods including the measurement of protein oxidation and redox balance or detecting ROS levels by low level chemiluminescence, lucigenin and luminol $(63,163-166)$. CAT activity was also found to change with ontogenetic transitions leading to conidiation $(109,124)$. CAT-3 activity is high during mycelial growth, and increases with adhesion of the mycelium, whereas in aerial hyphae, CAT-1 and CAT-3 display similar activities. In addition, enhanced hyphal adhesion with intense formation of aerial hyphae and conidia were found in cat- $3^{\text {rip }}$ mutant parallel with elevated protein oxidation suggesting that the hyperoxidant state promotes ontogenetic transition (110). CAT-1 activity increases and accumulates during the formation of conidia, where it is mainly bound to the wall of the spore (109). This CAT seems to be the prime CAT at this state. Total CAT activity is $\sim 60$ times higher in conidia than in growing mycelia. Differences in cat- 1 and cat-3 mRNA levels also reflect the activity changes measured during conidiation. In addition, progressive and state-dependent oxidation and degradation of both CAT-1 and CAT-3 were also observed during conidiation (109). CAT-2 activity is induced parallel with adhesion and aerial hyphae formation, and is also present in conidia (124).

\section{Regulation of the antioxidant system in Neurospora crassa}

Environmental stressors such as heat, ROS, osmotic stress, chemical compounds, and metal ions are known among others to stimulate members of the antioxidant system in various organisms (53).
Often, stimulation or induction of the antioxidant system can be observed in parallel with an increase in ROS production. In Neurospora, heat shock $\left(48^{\circ} \mathrm{C}\right)$ increases both the $\mathrm{O}_{2}{ }^{\bullet-}$ level and the peroxidase activity but does not influence the activity of SOD in liquid cultures of mycelia (94). Both the expression and the activity of CAT-2 and CAT- 3 are induced by heat shock and elevation of ROS levels $(78,109,173)$. In line with the above data, pretreatment with $\mathrm{H}_{2} \mathrm{O}_{2}$ increases thermotolerance. In contrast to cat-2 and cat-3, cat-1 RNA accumulates only upon nutrient depletion or in the presence of inadequate carbon source.

Menadione and paraquat (methyl-viologen) are $\mathrm{O}_{2}^{\bullet-}$ generating compounds. In sod-1 germination of conidia is severely affected in the presence of paraquat (182). On the other hand, menadione treatment promotes SOD and CAT activities and expression of cat-3 $(55,156)$. Similarly, upon addition of paraquat both cat-3 RNA level and CAT activity were increased in growing mycelia $(109,173)$. Further, menadione induces expression of several genes including oxidoreductases and factors of the thioredoxin and glutathione system. In contrast, neither of the four sod genes was induced in response to the relatively moderate level of menadione (156).

$\mathrm{H}_{2} \mathrm{O}_{2}$ increases peroxidase activity in mycelia (77-79) and induces the expression of genes playing a role in redox homeostasis, such as cat-2, cat-3, thioredoxin, and members of the glutathione system $(109,156,161)$. Parallel to the increase of RNA levels, CAT-3 activity is also enhanced upon $\mathrm{H}_{2} \mathrm{O}_{2}$ treatment of mycelia (109).

Several investigations were performed to examine the signaling pathways that control the antioxidant enzymes in Neurospora. GNA-1, a $\mathrm{G}_{\alpha \mathrm{i}}$ protein regulates the sensitivity to oxidative stress caused by $\mathrm{H}_{2} \mathrm{O}_{2}$, most probably by inhibiting the action and/or expression of enzymes important in the defense response (175). The activator protein-1 (AP-1) transcription factor controls gene expression in response to oxidative stress in both yeast and filamentous fungi. An AP-1like transcription factor, NcAP-1 is also expressed in Neurospora. Expression analysis based either on microarrays or quantitative real-time polymerase chain reaction revealed NcAP-1-dependent induction of several genes after treatment with menadione. (156). The products of most of these genes have not been identified yet. However, some of them belong to the thioredoxin and glutathione system or the family of oxidoreductases. A set of these genes showed NcAP-1dependent induction also in response to $\mathrm{H}_{2} \mathrm{O}_{2}$ (161). Another pathway controlling antioxidant enzymes is the p38 MAPK homologue OS-2 MAPK pathway in Neurospora crassa (173). The expression of three CATs, cat-1, cat-3, and cat-4 was found to be regulated by this pathway $(83,118,173,174)$. Detailed analysis of available microarray data related to the antioxidant and redox systems of Neurospora is beyond the scope of this review. However, for example, the transcription factors VAD-5, CRE-1, and CPC-1 may be regulators of the ROS homeostasis $(153,154,160)$. In addition, mutations in several serine-threonine protein kinases result in enhanced sensitivity to oxidative stress, suggesting the involvement of these kinases in the control of the antioxidant and redox system of Neurospora (123). Moreover, it is shown that the nucleoside diphosphate kinase-1 participates in the regulation of CAT-1 and CAT-3 $(87,170,182)$.

Finally, mutation of age, a possible regulator of oxidative stress responses leads to decreased CAT and cyanide-resistant 
SOD activity. The mutation also affects extracellular SOD activity (112).

\section{ROS enhance light responses in Neurospora crassa: a common point in light-sensing, ROS effects, and circadian timekeeping}

Light affects several physiological functions in fungi. In Neurospora crassa the most important light-controlled phenomena include enhancement of carotenoid biosynthesis, induction of conidiation, determination of perithecial polarity, positive phototropism of perithecial beaks, and phase shift in the circadian rhythm (24).

The shape of fertilized perithecia culminates with a beak that points upward under illumination. In contrast, beaks are randomly directed in cultures kept in darkness (120). However, in sod-1 the amount of upward perithecial beaks is reduced, suggesting that ROS are involved in the determination of perithecial polarity (179).

Light (including UV, blue, and visible light) is considered to stimulate generation of ROS. In most cases the antioxidant system is able to compensate the increased ROS production, and thus ROS levels are not significantly elevated. However, when either sod-1 or cat- 1 is mutated, light elevates ROS levels in Neurospora (180). It has been shown that conidia produce $\mathrm{O}_{2}{ }^{\bullet-}$, and light enhances this process (155). The product of the albino (al)-1 gene plays an essential role in carotenogenesis (90, 98) and carotenoids are part of the antioxidant system (see above). Accordingly, pronounced light-dependent protein oxidation was found in an al-1 mutant (99). Moreover, in germinating conidia ROS-evoked oxidation of CAT-1 increases with elevation of the light intensity, suggesting again that induction of ROS by light plays an important role in Neurospora in vivo (99). Light treatment reduces conidial germination rate in cat-1 $1^{\text {rip }}$ more significantly than does in $w t$, suggesting that light enhances ROS generation in this case as well (170). age mutants with defective antioxidant system die rapidly in light, whereas their lifespan is normal in the dark (114, 115). cat-1, cat-2, cat-4, and a putative sod are lightinducible genes, and light increases the overall CAT and SOD activity $(25,55,99,180)$. All these facts suggest that illumination-both directly and indirectly-results in the elevation of ROS production and promotes activity of the antioxidant system in Neurospora.

Light-activated carotenoid synthesis seems to be intensified by ROS as suggested by several data. For example, the lightinduced elevation of carotenoid content is higher in airexposed hyphae than in mycelia grown in liquid culture, and a high concentration of $\mathrm{O}_{2}$ further enhances the accumulation of carotenoids (75). Similarly, both the sod-1mutation and $\mathrm{H}_{2} \mathrm{O}_{2}$ treatment increase the light-stimulated expression of the different al genes and, as a consequence, the synthesis of carotenoids $(75,179)$. When, in turn, mycelia are treated with antioxidants, light-evoked accumulation of carotenoids and the al-1 RNA level is reduced as compared with the control (179). Finally, the high carotenoid production of the cat-3 and the sod-1 mutant in both light and dark suggests that ROS and light synergistically affect carotenogenesis $(110,179)$.

In summary, light is able to promote the activity and/or expression of various members of the antioxidant system, and ROS, in turn, can enhance the effect of light and/or mimic the light action in dark.
Light-induced carotenogenesis is dependent on the WCC, the main photoreceptor of Neurospora (95). The diminution of carotenoid synthesis in the double mutants $w c-1$, sod-1 and $w c-2$, sod-1 in both light and dark indicate that certain effects of ROS on these processes are dependent on the WCC (179). In addition, ROS also promote transcription of light-dependent genes that are not involved in carotenogenesis, such as frq, $w c-1$, and bli-4 (a mitochondrial short-chain alcohol dehydrogenase-like protein) $(179,181)$. In conclusion, light and ROS often induce the same physiological responses by activating pathways that, at least partially, converge on the WCC.

\section{Interactions Between ROS Homeostasis and the Circadian Clock in Neurospora}

\section{Circadian regulation of the actors of ROS homeostasis}

In a recent work Yoshida et al. showed that Neurospora displays rhythmic ROS production in constant darkness (180). In these experiments, ROS levels were determined in the growth fronts of race tube cultures by using a lucigeninenhanced chemiluminescence assay that is primarily sensitive to $\mathrm{O}_{2}{ }^{\bullet-}$. Peak and trough levels can be detected in the middle of the subjective night and at midday, respectively. Similar oscillations of ROS have been observed in $b d$, $w t$, and the clock mutants $f r q^{10}, \Delta w c-1$, and $\Delta w c-2$, indicating that a FLO is involved in the regulation. However, average ROS levels are reduced in the clock mutants as compared with $w t$. Further, the ROS rhythm displays a significantly higher amplitude in $b d$ than in the other strains, suggesting that RAS signaling affects the regulation of ROS oscillation. Interestingly, although the temporal changes of ROS levels are retained in $12 / 12 \mathrm{~h}$ LD-cycles in $w t$, peak ROS levels are delayed by about $6 \mathrm{~h}$ as compared with constant darkness (DD).

Under free-running conditions on race tubes, NOX-1 activity was found to be a major source of ROS and was required for the oscillation of ROS levels (180). However, cellular NOX activity does not oscillate, suggesting that the rhythm is likely to be generated by a ROS-destroying mechanism. Indeed, cellular CAT activity was found to display a low-amplitude rhythm and thus may be involved in the generation of ROS rhythm. It is still unclear which of the four Neurospora CATs plays a dominant role in this process, and the data are not fully consistent. cat-1 RNA expression displays a circadian rhythm that is controlled by the WCC via the OS-2 MAPK pathway $(83,173)$. Although the cat-1 expression pattern does not fit the time-dependent changes in CAT activity, the dampened ROS oscillation in a cat-1 loss-of-function mutant suggests that CAT-1 activity is required for maintaining ROS rhythm. On the other hand, despite the loss of cat-1 rhythm, in both the $w c-1$ and the $w c-2$ mutant oscillating ROS levels can be detected (180). Under constant conditions the amplitude of ROS oscillation gradually increases in the first few days, parallel with reduction of the daily maxima of CAT activity. This observation indicates again that circadian regulation of ROS levels is mediated, at least partially, by the oscillating CAT activity (180).

In constant darkness, when Neurospora displays rhythmic conidiation, the clear differences in the NAD(P)H:NAD(P) ratio between band and interband regions also suggest that circadian timekeeping plays a role in the control of the redoxbalance of the cell (15). In addition, clock mutants have an altered pattern of CAT and SOD activity during ontogenesis 
(54). However, an important aspect should be considered when ROS levels are examined on solid media; independent of the clock effect, both carotenogenesis and CAT activity change as a function of developmental state. For example, in the late subjective night, when conidia are formed, the increased cat-1 expression typical for this developmental transition may be partially responsible for the reduction of ROS levels (109). During the same period carotenoids are produced in the conidia that, acting as antioxidants, may also contribute to the decrease of cellular ROS concentration (7). To better distinguish between direct and indirect (developmentmediated) effects of the circadian clock on the ROS homeostasis, rhythms of ROS levels and/or CAT activity could be investigated in strains that develop very few conidia (e.g., the fluffy mutant) $(6,57)$.

Chipseq analysis of CSP-1 binding sites and microarray data with clock (wc-1 and $w c-2)$ and vvd mutants also reveal the possibility that several genes playing a role in the ROS homeostasis of Neurospora crassa is under the control of the FWO $(132,141)$.

Very recently, rhythmic oxidation of the $\mathrm{H}_{2} \mathrm{O}_{2}$-scavenging protein peroxiredoxin was reported also in Neurospora (47). The peak levels of oxidized peroxiredoxin coincide well with the maxima of ROS production determined by Yoshida et al. (180). This oxidation rhythm does not need a functional FWO; the phase is, however, altered in the frq-less mutant as compared with wt. Further, in a long-period mutant, peroxiredoxin oxidation cycles display a lengthened period, with a phase reflecting the altered oscillation in FRQ abundance. These data also suggest a close alignment of the oxidation rhythm with the FWO. Based on these observations, it is tempting to speculate that in Neurospora, like in other organisms, a post-translational oscillator based on or coupled to the peroxiredoxin system may function in the cytosol, although tightly interconnected with the well-described TTFL, the FWO $(47,119)$.

\section{ROS-controlled rhythms in Neurospora}

When ROS levels are increased in Neurospora, either by the addition of the ROS generator menadione or by the mutation of sod-1, a robust and sustained conidiation rhythm can be detected in constant darkness, whereas wt does not display a clear banding pattern under the same conditions (Fig. 1B) (12, 181). However, the self-sustained conidial banding of the sod1 mutant depends on the nutritional conditions; it is rhythmic on minimal medium and on medium complemented with glycerol, but arrhythmic when the medium contains sucrose or glucose $(61,181)$. This suggests that the impact of SOD-1 on the conidiation rhythm is dependent on the metabolism. sod-1 can be entrained to photocycles with very low light intensities, in line with the increased light sensitivity of the strain. The transcription factor Fluffy, a major regulator of conidiation was proposed as a possible linker between ROS production and rhythmic conidiation $(12,151)$. Indeed, the amplitude of the oscillating fluffy expression is markedly increased in the sod-1 mutant, in accordance with the more pronounced banding.

In contrast to the sod-1 mutant, in a sod-1, bd strain no clear banding was observed (181). However, this strain grew very slowly and showed excessive conidiation, rendering it more difficult to evaluate the race tubes. Interestingly, when the sod-1 mutation was combined with a loss-of-function mutation in $f r q\left(f r q^{10}\right)$, self-sustained conidial banding was observed in constant darkness, indicating the operation of an FLO (181). However, this rhythm was not tested for temperature compensation and was masked by light during photoperiods. Thus, under entrained conditions this FLO is not able to govern the conidiation rhythm.

Similar to the effect of the sod-1 mutation, addition of menadione in relatively high concentration induces conidiation rhythm in clock mutants, which can be observed in both DD and constant light (LL). However, it is important to note that, in contrast to the banding of $\operatorname{sod}-1, \mathrm{frq}^{10}$, these rhythms can only be detected on plates but not on race tubes $(16,61)$. This may indicate that the menadione-induced banding has a high sensitivity to $\mathrm{CO}_{2}$. The mechanisms underlying the regulation of these rhythms seem to be heterogeneous, that is, while both $b d, f r q^{10}$ and $b d, w c-1$ display very short periods (15 and $14 \mathrm{~h}$, respectively), $b d, w c-2$ is a long period $(25 \mathrm{~h})$ mutant. In addition, while the period of the menadione-induced rhythm of $b d, w c-2$ is compensated in a relatively wide temperature range, this range is rather narrow in case of $b d, f r q^{10}$. Interestingly, in the presence of menadione even $b d$ displayed rhythmic conidiation in LL. However, the period was very sensitive to light intensity, varying in the range from 22 to $15 \mathrm{~h}$ (16). Only mutants lacking frq or $c s p-1$ were entrainable to $12 / 12 \mathrm{~h}$ LD-cycles. The other strains including $b d$ produced two bands in each cycle, one in the dark and then another in response to light. Thus, menadione apparently strengthens the masking effect of light. In summary, elevated ROS levels can induce circadian or circadian-like conidiation rhythms that are partially independent of the FWO. However, these oscillations are usually sensitive to the culturing conditions acting probably via metabolic pathways.

In addition to inducing or strengthening circadian outputs, ROS also affect the most important parameters of the rhythm, that is, the period length in constant darkness and the phase under entrained conditions (61). Elevation of ROS levels, particularly that of $\mathrm{O}_{2}^{\bullet-}$ either genetically (sod-1 mutant) or by the addition of a ROS generator (menadione) results in an advance of the conidiation phase in both photoand temperature cycles. In addition, the phase in sod-1 is more sensitive to menadione than in wt indicating the dominant role of $\mathrm{O}_{2}{ }^{\bullet-}$. In contrast to sod-1, mutation of sod-2 has no effect on the phase. Thus, $\mathrm{O}_{2}{ }^{\bullet-}$ accessible for SOD-1 rather than for SOD-2 appears to affect the timing of conidiation. On the other hand, reduction of basal ROS levels delays the phase, indicating that ROS affect circadian timekeeping even under non-stress conditions. Although CAT-1 was shown to slightly affect rhythmic ROS production under free run conditions (180), the timing of conidiation in cat-1 did not differ from that in wt suggesting that CAT-1 activity is not a limiting factor in determination of the phase in LD cycles. Since nox mutants display phases similar to that of the control, a NOX independent source of $\mathrm{O}_{2}{ }^{\bullet-}$, most probably metabolic activity may regulate the timing of banding.

In photocycles, temperature differences are reflected by slight variations of the phase of banding (61). The extent of this fine-tuning effect of temperature is dependent on the antioxidant $N$-acetyl-L-cysteine or the mutation of sod-1 suggesting that differences in ROS production may mediate temperature effects toward the circadian clock. 
An increased ROS level also advances the phase of frq expression and shortens the circadian period in Neurospora, suggesting that ROS affect the molecular oscillator. Elevation of ROS levels also increases PP2A activity and accelerates dephosphorylation of the WCC in the dark. These data suggest a model in which ROS-dependent changes in PP2A activity results in later or earlier reactivation of the WCC and thereby advance or delay the oscillator, respectively (61).

However, another plausible and most probably parallelacting mechanism of ROS-evoked activation of the WCC was also proposed. In an in vitro assay, enhanced binding of the WCC to the clock-box was shown in the presence of $\mathrm{H}_{2} \mathrm{O}_{2}$. It was therefore speculated that ROS may act on the WCC by promoting the formation of the flavin-cysteinyl adduct and thus by mimicking the effect of light (180). Future investigations should clarify whether the other LOV domain-containing photoreceptor VVD is also involved in the mediation of ROS-induced responses of the circadian clock.

In summary, the above data indicate that the circadian oscillator is controlled by cellular ROS levels. Changes in ROS levels may mediate the effect of even basal fluctuations of the metabolism to the clock machinery.

\section{Conclusions}

A model of the possible interconnections of ROS signaling and circadian timekeeping is outlined in Figure 5. A classical circadian oscillator is based on a TTFL mechanism, called FWO in Neurospora. Several members of ROS homeostasis are under the control of the TTFL circadian oscillator, and ROS levels display circadian oscillation. Besides the wellestablished oscillations of some actors in the redox system (e.g., CAT activity), TTFL may control ROS levels by at least two additional mechanisms. First, FWO is considered to regulate certain segments of metabolism, and metabolism is one of the main sources of ROS. Second, ROS homeostasis changes progressively during morphogenetic transitions leading to conidiation, and conidiation is under the control of FWO. Thus, rhythmic changes of ROS levels may be both directly and indirectly regulated by the FWO. Light is able to increase ROS levels and shift the TTFL clock. Light and ROS signaling converge, at least partially, on the positive factor of the TTFL. ROS affect the ticking of the TTFL clock and thus contribute to the determination of the period and, more significantly, of the phase. ROS were also shown to increase the amplitude of the FWO. More robustness of the rhythm and thus a better adaptive feature of the organism might be of advantage under stress conditions (in the present case, oxidative stress). Moreover, ROS can enhance the output of the TTFL clock, but the exact pathway mediating this effect is not known yet.

ROS also enhance phenotypic expression of non-classical oscillators in the absence of core clock components. However, the question arises whether these oscillators are robust enough to prepare the organism for cycling changes of the surroundings under natural conditions.

Peroxiredoxins affect ROS levels due to their ability to reduce hydroperoxides. Although the oxydation cycle of peroxiredoxins is not dependent on the FWO, it is certainly influenced by the classical TTFL. One can speculate that alterations in ROS levels - especially in the levels of hydroperoxides - may influence this process, and vice versa, peroxiredoxin-dependent changes in ROS levels may feed back on the FWO.

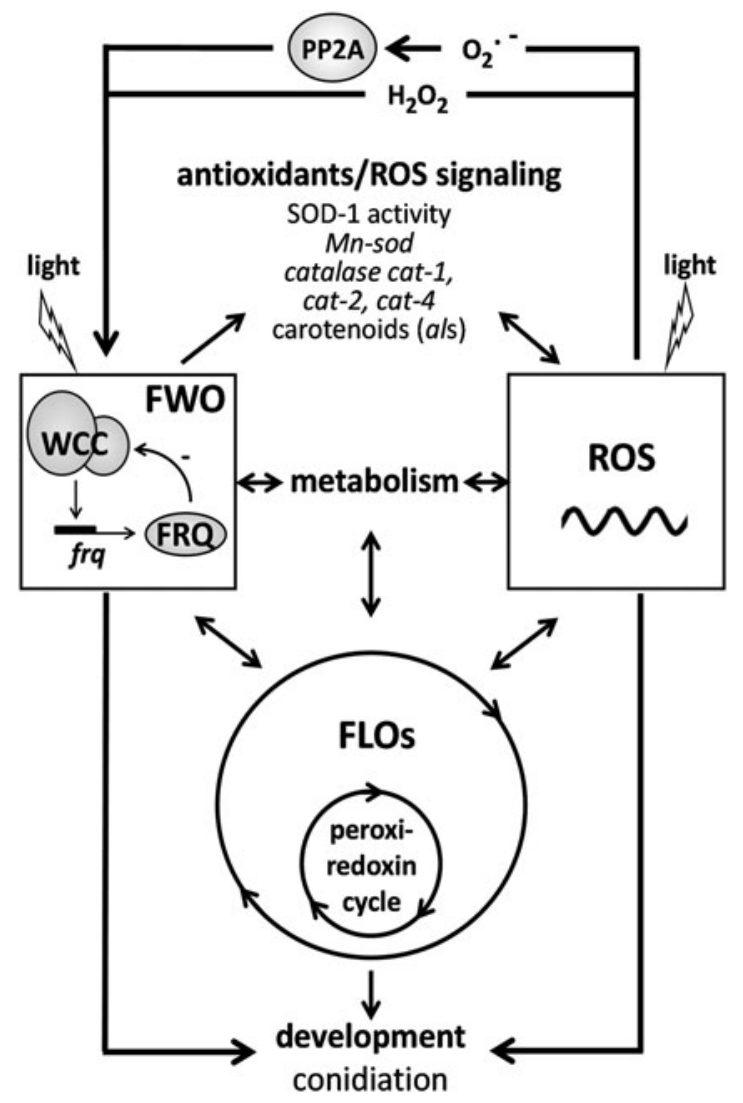

FIG. 5. Possible interconnections of the ROS system and the main circadian clock of Neurospora, the FWO. FWO affects ROS levels by controlling members of both the antioxidant system and metabolism. In turn, ROS may affect the FWO by determining the amplitude, phase, and period length. ROS promote the manifestation of a rhythmic phenotype even in the absence of FWO. This may be mediated by enhancing the ticking of a FLO or by acting at the level of output. The peroxiredoxin oscillator represents a FLO that does not contain a TTFL, and is interconnected with the FWO. In turn, peroxiredoxin also determines the ROS levels. Light promotes formation of ROS, and light and ROS signaling converge on the positive factor of the FWO. FLO, FRQ-less oscillator; TTFL, transcription-translation feedback loop.

Increasing evidence suggests an intensive interplay between metabolism and circadian timekeeping $(11,65,139)$. A possible model of this interplay consists of at least two oscillators, one based on a TTFL and another one functioning at a post-transcriptional level. TTFL drives rhythmic fluctuations in the metabolism, but simultaneously environmental signals, for example, changes in the availability of nutrients, rapidly modulate or re-entrain metabolic oscillations via posttranslational mechanisms. Interconnections between these oscillators could enable a gradual and smooth harmonization between the cogwheels of the different oscillators, a process required for effective adaptation. ROS may represent bidirectional mediators of this process.

\section{References}

1. Aguirre J and Lambeth JD. Nox enzymes from fungus to fly to fish and what they tell us about Nox function in mammals. Free Radic Biol Med 49: 1342-1353, 2010. 
2. Aguirre J, Rios-Momberg M, Hewitt D, and Hansberg W. Reactive oxygen species and development in microbial eukaryotes. Trends Microbiol 13: 111-118, 2005.

3. Aronson BD, Johnson KA, and Dunlap JC. Circadian clock locus frequency: protein encoded by a single open reading frame defines period length and temperature compensation. Proc Natl Acad Sci U S A 91: 7683-7687, 1994.

4. Aronson BD, Johnson KA, Loros JJ, and Dunlap JC. Negative feedback defining a circadian clock: autoregulation of the clock gene frequency. Science 263: 1578-1584, 1994.

5. Bai Z, Harvey LM, and McNeil B. Oxidative stress in submerged cultures of fungi. Crit Rev Biotechnol 23: 267-302, 2003.

6. Bailey LA and Ebbole DJ. The fluffy gene of Neurospora crassa encodes a Gal4p-type C6 zinc cluster protein required for conidial development. Genetics 148: 1813-1820, 1998.

7. Baima S, Carattoli A, Macino G, and Morelli G. Photoinduction of albino-3 gene expression in Neurospora crassa conidia. J Photochem Photobiol B 15: 233-238, 1992.

8. Baker CL, Loros JJ, and Dunlap JC. The circadian clock of Neurospora crassa. FEMS Microbiol Rev 36: 95-110, 2012.

9. Ballario P, Talora C, Galli D, Linden H, and Macino G. Roles in dimerization and blue light photoresponse of the PAS and LOV domains of Neurospora crassa white collar proteins. Mol Microbiol 29: 719-729, 1998.

10. Ballario P, Vittorioso P, Magrelli A, Talora C, Cabibbo A, and Macino G. White collar-1, a central regulator of blue light responses in Neurospora, is a zinc finger protein. EMBO J 15: 1650-1657, 1996.

11. Bass J and Takahashi JS. Circadian integration of metabolism and energetics. Science 330: 1349-1354, 2010.

12. Belden WJ, Larrondo LF, Froehlich AC, Shi M, Chen $\mathrm{CH}$, Loros JJ, and Dunlap JC. The band mutation in Neurospora crassa is a dominant allele of ras- 1 implicating RAS signaling in circadian output. Genes Dev 21: 1494-1505, 2007.

12a. Belden WJ, Loros JJ, and Dunlap JC. Execution of the circadian negative feedback loop in Neurospora requires the ATP-dependent chromatin-remodeling enzyme CLOCKSWITCH. Mol Cell 25: 587-600, 2007.

13. Belden WJ, Lewis ZA, Selker EU, Loros JJ, and Dunlap JC. CHD1 remodels chromatin and influences transient DNA methylation at the clock gene frequency. PLoS Genet 7: e1002166, 2011.

14. Belozerskaia TA and Gessler NN. [Reactive oxygen species and the strategy of the antioxidant defense in fungi: a review]. Appl Biochem Microbiol 43: 565-575, 2007 [Article in Russian].

15. Brody S and Harris S. Circadian rhythms in Neurospora: spatial differences in pyridine nucleotide levels. Science 180: 498-500, 1973.

16. Brody S, Oelhafen K, Schneider K, Perrino S, Goetz A, Wang C, and English C. Circadian rhythms in Neurospora crassa: downstream effectors. Fungal Genet Biol 47: 159-168, 2010.

17. Cano-Dominguez N, Alvarez-Delfin $\mathrm{K}$, Hansberg W, and Aguirre J. NADPH oxidases NOX-1 and NOX-2 require the regulatory subunit NOR-1 to control cell differentiation and growth in Neurospora crassa. Eukaryot Cell 7: 1352-1361, 2008.

18. Carneiro P, Duarte M, and Videira A. Disruption of alternative $\mathrm{NAD}(\mathrm{P}) \mathrm{H}$ dehydrogenases leads to decreased mitochondrial ROS in Neurospora crassa. Free Radic Biol Med 52: 402-409, 2012.
19. Cha J, Chang SS, Huang G, Cheng P, and Liu Y. Control of WHITE COLLAR localization by phosphorylation is a critical step in the circadian negative feedback process. EMBO J 27: 3246-3255, 2008.

20. Chary P, Dillon D, Schroeder AL, and Natvig DO. Superoxide dismutase (sod-1) null mutants of Neurospora crassa: oxidative stress sensitivity, spontaneous mutation rate and response to mutagens. Genetics 137: 723-730, 1994.

21. Chary P, Hallewell RA, and Natvig DO. Structure, exon pattern, and chromosome mapping of the gene for cytosolic copper-zinc superoxide dismutase (sod-1) from Neurospora crassa. J Biol Chem 265: 18961-18967, 1990.

22. Chary P and Natvig DO. Evidence for three differentially regulated catalase genes in Neurospora crassa: effects of oxidative stress, heat shock, and development. J Bacteriol 171: 2646-2652, 1989.

23. Chen CH, DeMay BS, Gladfelter AS, Dunlap JC, and Loros JJ. Physical interaction between VIVID and white collar complex regulates photoadaptation in Neurospora. Proc Natl Acad Sci U S A 107: 16715-16720, 2010.

24. Chen $\mathrm{CH}$, Dunlap JC, and Loros JJ. Neurospora illuminates fungal photoreception. Fungal Genet Biol 47: 922-929, 2010.

25. Chen $\mathrm{CH}$, Ringelberg CS, Gross RH, Dunlap JC, and Loros JJ. Genome-wide analysis of light-inducible responses reveals hierarchical light signalling in Neurospora. EMBO J 28: 1029-1042, 2009.

26. Cheng P, He Q, Wang L, and Liu Y. Regulation of the Neurospora circadian clock by an RNA helicase. Genes Dev 19: 234-241, 2005.

27. Cheng P, Yang Y, Gardner KH, and Liu Y. PAS domainmediated WC-1/WC-2 interaction is essential for maintaining the steady-state level of WC-1 and the function of both proteins in circadian clock and light responses of Neurospora. Mol Cell Biol 22: 517-524, 2002.

28. Cheng P, Yang Y, Heintzen C, and Liu Y. Coiled-coil domain-mediated FRQ-FRQ interaction is essential for its circadian clock function in Neurospora. EMBO J 20: 101-108, 2001.

29. Cheng $\mathrm{P}$, Yang Y, Wang L, He Q, and Liu Y. WHITE COLLAR-1, a multifunctional Neurospora protein involved in the circadian feedback loops, light sensing, and transcription repression of wc-2. J Biol Chem 278: 3801-3808, 2003.

30. Christensen MK, Falkeid G, Loros JJ, Dunlap JC, Lillo C, and Ruoff P. A nitrate-induced frq-less oscillator in Neurospora crassa. J Biol Rhythms 19: 280-286, 2004.

31. Circu ML and Aw TY. Reactive oxygen species, cellular redox systems, and apoptosis. Free Radic Biol Med 48: 749$762,2010$.

32. Colot HV, Loros JJ, and Dunlap JC. Temperature-modulated alternative splicing and promoter use in the Circadian clock gene frequency. Mol Biol Cell 16: 5563-5571, 2005.

33. Correa A, Lewis ZA, Greene AV, March IJ, Gomer RH, and Bell-Pedersen D. Multiple oscillators regulate circadian gene expression in Neurospora. Proc Natl Acad Sci U S A 100: 13597-13602, 2003.

34. Crosthwaite SK, Dunlap JC, and Loros JJ. Neurospora wc-1 and wc-2: transcription, photoresponses, and the origins of circadian rhythmicity. Science 276: 763-769, 1997.

35. Davies KJ. Degradation of oxidized proteins by the $20 \mathrm{~S}$ proteasome. Biochimie 83: 301-310, 2001

36. de Paula RM, Lewis ZA, Greene AV, Seo KS, Morgan LW, Vitalini MW, Bennett L, Gomer RH, and Bell-Pedersen D. Two circadian timing circuits in Neurospora crassa cells share components and regulate distinct rhythmic processes. J Biol Rhythms 21: 159-168, 2006. 
37. Dean RT, Fu S, Stocker R, and Davies MJ. Biochemistry and pathology of radical-mediated protein oxidation. Biochem J 324 (Pt 1): 1-18, 1997.

38. Diaz A, Horjales E, Rudino-Pinera E, Arreola R, and Hansberg W. Unusual Cys-Tyr covalent bond in a large catalase. J Mol Biol 342: 971-985, 2004.

39. Diaz A, Rangel P, Montes de Oca Y, Lledias F, and Hansberg W. Molecular and kinetic study of catalase-1, a durable large catalase of Neurospora crassa. Free Radic Biol Med 31: 1323-1333, 2001.

40. Diaz A, Valdes VJ, Rudino-Pinera E, Horjales E, and Hansberg W. Structure-function relationships in fungal large-subunit catalases. J Mol Biol 386: 218-232, 2009.

41. Diernfellner A, Colot HV, Dintsis O, Loros JJ, Dunlap JC, and Brunner M. Long and short isoforms of Neurospora clock protein FRQ support temperature-compensated circadian rhythms. FEBS Lett 581: 5759-5764, 2007.

42. Diernfellner AC, Schafmeier T, Merrow MW, and Brunner M. Molecular mechanism of temperature sensing by the circadian clock of Neurospora crassa. Genes Dev 19: 1968-1973, 2005.

43. Dominguez L, Sosa-Peinado A, and Hansberg W. Catalase evolved to concentrate $\mathrm{H}_{2} \mathrm{O}_{2}$ at its active site. Arch Biochem Biophys 500: 82-91, 2010.

44. Dong W, Tang X, Yu Y, Griffith J, Nilsen R, Choi D, Baldwin J, Hilton L, Kelps K, McGuire J, Morgan R, Smith M, Case M, Arnold J, Schuttler HB, Wang Q, Liu J, Reeves J, and Logan D. Systems biology of the Neurospora biological clock. IET Syst Biol 1: 257-265, 2007.

45. Dong W, Tang X, Yu Y, Nilsen R, Kim R, Griffith J, Arnold $\mathrm{J}$, and Schuttler HB. Systems biology of the clock in Neurospora crassa. PLoS One 3: e3105, 2008.

46. Dragovic Z, Tan Y, Gorl M, Roenneberg T, and Merrow M. Light reception and circadian behavior in 'blind' and 'clock-less' mutants of Neurospora crassa. EMBO J 21: 36433651, 2002.

47. Edgar RS, Green EW, Zhao Y, van Ooijen G, Olmedo M, Qin X, Xu Y, Pan M, Valekunja UK, Feeney KA, Maywood ES, Hastings MH, Baliga NS, Merrow M, Millar AJ, Johnson $\mathrm{CH}$, Kyriacou $\mathrm{CP}, \mathrm{O}^{\prime}$ Neill JS, and Reddy AB. Peroxiredoxins are conserved markers of circadian rhythms. Nature 485: 459-464, 2012.

48. Elvin M, Loros JJ, Dunlap JC, and Heintzen C. The PAS/ LOV protein VIVID supports a rapidly dampened daytime oscillator that facilitates entrainment of the Neurospora circadian clock. Genes Dev 19: 2593-2605, 2005.

49. Fahey RC, Brody S, and Mikolajczyk SD. Changes in the glutathione thiol-disulfide status of Neurospora crassa conidia during germination and aging. J Bacteriol 121: 144-151, 1975.

50. Finkel T. Oxidant signals and oxidative stress. Curr Opin Cell Biol 15: 247-254, 2003.

51. Franchi L, Fulci V, and Macino G. Protein kinase C modulates light responses in Neurospora by regulating the blue light photoreceptor WC-1. Mol Microbiol 56: 334-345, 2005.

52. Garceau NY, Liu Y, Loros JJ, and Dunlap JC. Alternative initiation of translation and time-specific phosphorylation yield multiple forms of the essential clock protein FREQUENCY. Cell 89: 469-476, 1997.

53. Gessler NN, Aver'yanov AA, and Belozerskaya TA. Reactive oxygen species in regulation of fungal development. Biochemistry (Mosc) 72: 1091-1109, 2007.

54. Gessler NN, Leonovich OA, Rabinovich Ia M, Rudchenko $\mathrm{MN}$, and Belozerskaia TA. [A comparative study of the components of the antioxidant defense system during growth of the mycelium of a wild-type Neurospora crassa strain and mutants, white collar-1 and white collar-2]. Appl Biochem Microbiol 42: 332-337, 2006.

55. Gessler NN, Sokolov AV, Bykhovskii V, and Belozerskaia TA. [Superoxide dismutase and catalase activities in carotenoid-synthesizing fungi Blakeslea trispora and Neurospora crassa under the oxidative stress]. Appl Biochem Microbiol 38: 237-242, 2002 [Article in Russian].

56. Gin E, Diernfellner AC, Brunner M, and Hofer T. The Neurospora photoreceptor VIVID exerts negative and positive control on light sensing to achieve adaptation. Mol Syst Biol 9: 667, 2013.

57. Gooch VD, Mehra A, Larrondo LF, Fox J, Touroutoutoudis M, Loros JJ, and Dunlap JC. Fully codon-optimized luciferase uncovers novel temperature characteristics of the Neurospora clock. Eukaryot Cell 7: 28-37, 2008.

58. Gorl M, Merrow M, Huttner B, Johnson J, Roenneberg T, and Brunner M. A PEST-like element in FREQUENCY determines the length of the circadian period in Neurospora crassa. EMBO J 20: 7074-7084, 2001.

59. Granshaw T, Tsukamoto M, and Brody S. Circadian rhythms in Neurospora crassa: farnesol or geraniol allow expression of rhythmicity in the otherwise arrhythmic strains frq10, wc-1, and wc-2. J Biol Rhythms 18: 287-296, 2003.

60. Guo J, Cheng P, and Liu Y. Functional significance of FRH in regulating the phosphorylation and stability of Neurospora circadian clock protein FRQ. J Biol Chem 285: 1150811515, 2010.

61. Gyongyosi N, Nagy D, Makara K, Ella K, and Kaldi K. Reactive oxygen species can modulate circadian phase and period in Neurospora crassa. Free Radic Biol Med 58C: 134143, 2012.

62. Hansberg W and Aguirre J. Hyperoxidant states cause microbial cell differentiation by cell isolation from dioxygen. J Theor Biol 142: 201-221, 1990.

63. Hansberg W, de Groot H, and Sies H. Reactive oxygen species associated with cell differentiation in Neurospora crassa. Free Radic Biol Med 14: 287-293, 1993.

64. Hansberg W, Salas-Lizana R, and Dominguez L. Fungal catalases: function, phylogenetic origin and structure. Arch Biochem Biophys 525: 170-180, 2012.

65. Hatori M, Vollmers C, Zarrinpar A, DiTacchio L, Bushong EA, Gill S, Leblanc M, Chaix A, Joens M, Fitzpatrick JA, Ellisman $\mathrm{MH}$, and Panda S. Time-restricted feeding without reducing caloric intake prevents metabolic diseases in mice fed a high-fat diet. Cell Metab 15: 848-860, 2012.

66. He Q, Cha J, Lee HC, Yang Y, and Liu Y. CKI and CKII mediate the FREQUENCY-dependent phosphorylation of the WHITE COLLAR complex to close the Neurospora circadian negative feedback loop. Genes Dev 20: 2552-2565, 2006.

67. He Q, Cheng P, Yang Y, Wang L, Gardner KH, and Liu Y. White collar-1, a DNA binding transcription factor and a light sensor. Science 297: 840-843, 2002.

68. He Q, Cheng P, Yang Y, Yu H, and Liu Y. FWD1-mediated degradation of FREQUENCY in Neurospora establishes a conserved mechanism for circadian clock regulation. EMBO J 22: 4421-4430, 2003.

69. He $\mathrm{Q}$ and Liu Y. Molecular mechanism of light responses in Neurospora: from light-induced transcription to photoadaptation. Genes Dev 19: 2888-2899, 2005.

70. Heintzen C, Loros JJ, and Dunlap JC. The PAS protein VIVID defines a clock-associated feedback loop that represses light input, modulates gating, and regulates clock resetting. Cell 104: 453-464, 2001. 
71. Henry LE, Cammack R, Schwitzguebel JP, Palmer JM, and Hall DO. Intracellular localization, isolation and characterization of two distinct varieties of superoxide dismutase from Neurospora crassa. Biochem J 187: 321-328, 1980.

72. Huang G, Chen S, Li S, Cha J, Long C, Li L, He Q, and Liu $\mathrm{Y}$. Protein kinase A and casein kinases mediate sequential phosphorylation events in the circadian negative feedback loop. Genes Dev 21: 3283-3295, 2007.

73. Hunt SM, Elvin M, Crosthwaite SK, and Heintzen C. The PAS/LOV protein VIVID controls temperature compensation of circadian clock phase and development in Neurospora crassa. Genes Dev 21: 1964-1974, 2007.

74. Hunt SM, Thompson S, Elvin M, and Heintzen C. VIVID interacts with the WHITE COLLAR complex and FREQUENCY-interacting RNA helicase to alter light and clock responses in Neurospora. Proc Natl Acad Sci U S A 107: 16709-16714, 2010.

75. Iigusa H, Yoshida $Y$, and Hasunuma K. Oxygen and hydrogen peroxide enhance light-induced carotenoid synthesis in Neurospora crassa. FEBS Lett 579: 4012-4016, 2005.

76. Kaldi K, Gonzalez BH, and Brunner M. Transcriptional regulation of the Neurospora circadian clock gene wc-1 affects the phase of circadian output. EMBO Rep 7: 199-204, 2006.

77. Kapoor M and Lewis J. Heat shock induces peroxidase activity in Neurospora crassa and confers tolerance toward oxidative stress. Biochem Biophys Res Commun 147: 904-910, 1987.

78. Kapoor M, Sreenivasan GM, Goel N, and Lewis J. Development of thermotolerance in Neurospora crassa by heat shock and other stresses eliciting peroxidase induction. $J$ Bacteriol 172: 2798-2801, 1990.

79. Kapoor M and Sveenivasan GM. The heat shock response of Neurospora crassa: stress-induced thermotolerance in relation to peroxidase and superoxide dismutase levels. Biochem Biophys Res Commun 156: 1097-1102, 1988.

80. Kodadek T, Sikder D, and Nalley K. Keeping transcriptional activators under control. Cell 127: 261-264, 2006.

81. Lakin-Thomas PL. Circadian clock genes frequency and white collar-1 are not essential for entrainment to temperature cycles in Neurospora crassa. Proc Natl Acad Sci U S A 103: 4469-4474, 2006.

82. Lakin-Thomas PL and Brody S. Circadian rhythms in Neurospora crassa: lipid deficiencies restore robust rhythmicity to null frequency and white-collar mutants. Proc Natl Acad Sci U S A 97: 256-261, 2000.

83. Lamb TM, Finch KE, and Bell-Pedersen D. The Neurospora crassa OS MAPK pathway-activated transcription factor ASL-1 contributes to circadian rhythms in pathway responsive clockcontrolled genes. Fungal Genet Biol 49: 180-188, 2012.

84. Lamb TM, Goldsmith CS, Bennett L, Finch KE, and BellPedersen D. Direct transcriptional control of a p38 MAPK pathway by the circadian clock in Neurospora crassa. PLoS One 6: e27149, 2011.

85. Lambeth JD. NOX enzymes and the biology of reactive oxygen. Nat Rev Immunol 4: 181-189, 2004.

86. Lavi R, Shainberg A, Friedmann H, Shneyvays V, Rickover O, Eichler M, Kaplan D, and Lubart R. Low energy visible light induces reactive oxygen species generation and stimulates an increase of intracellular calcium concentration in cardiac cells. J Biol Chem 278: 40917-40922, 2003.

87. Lee B, Yoshida Y, and Hasunuma K. Nucleoside diphosphate kinase-1 regulates hyphal development via the transcriptional regulation of catalase in Neurospora crassa. FEBS Lett 583: 3291-3295, 2009.

88. Lee K, Loros JJ, and Dunlap JC. Interconnected feedback loops in the Neurospora circadian system. Science 289: 107110,2000

89. Lewis ZA, Correa A, Schwerdtfeger C, Link KL, Xie X, Gomer RH, Thomas T, Ebbole DJ, and Bell-Pedersen D. Overexpression of White Collar-1 (WC-1) activates circadian clock-associated genes, but is not sufficient to induce most light-regulated gene expression in Neurospora crassa. Mol Microbiol 45: 917-931, 2002.

90. Li C and Schmidhauser TJ. Developmental and photoregulation of al-1 and al-2, structural genes for two enzymes essential for carotenoid biosynthesis in Neurospora. Dev Biol 169: 90-95, 1995.

91. Li S and Lakin-Thomas P. Effects of prd circadian clock mutations on FRQ-less rhythms in Neurospora. J Biol Rhythms 25: 71-80, 2010.

92. Li S, Motavaze K, Kafes E, Suntharalingam S, and LakinThomas P. A new mutation affecting FRQ-less rhythms in the circadian system of Neurospora crassa. PLoS Genet 7: e1002151, 2011.

93. Liang JY, Yuann JM, Cheng CW, Jian HL, Lin CC, and Chen LY. Blue light induced free radicals from riboflavin on E. coli DNA damage. J Photochem Photobiol B 119: 60-64, 2013.

94. Lin WS and Kapoor M. Increase in superoxide production by heat-shocked cells of Neurospora crassa, demonstrated by a fluorometric assay. Int J Biochem 24: 1081-1086, 1992.

95. Linden H and Macino G. White collar 2, a partner in bluelight signal transduction, controlling expression of lightregulated genes in Neurospora crassa. EMBO J 16: 98-109, 1997.

96. Liu Y, Garceau NY, Loros JJ, and Dunlap JC. Thermally regulated translational control of FRQ mediates aspects of temperature responses in the Neurospora circadian clock. Cell 89: 477-486, 1997.

97. Liu Y, Merrow M, Loros JJ, and Dunlap JC. How temperature changes reset a circadian oscillator. Science 281: 825829, 1998.

98. Lledias F, Rangel P, and Hansberg W. Oxidation of catalase by singlet oxygen. J Biol Chem 273: 10630-10637, 1998.

99. Lledias F, Rangel P, and Hansberg W. Singlet oxygen is part of a hyperoxidant state generated during spore germination. Free Radic Biol Med 26: 1396-1404, 1999.

100. Lockwood DB, Wataha JC, Lewis JB, Tseng WY, Messer $\mathrm{RL}$, and Hsu SD. Blue light generates reactive oxygen species (ROS) differentially in tumor vs. normal epithelial cells. Dent Mater 21: 683-688, 2005.

101. Lombardi L, Schneider K, Tsukamoto M, and Brody S. Circadian rhythms in Neurospora crassa: clock mutant effects in the absence of a frq-based oscillator. Genetics 175: 1175-1183, 2007.

102. Lord KM and Read ND. Perithecium morphogenesis in Sordaria macrospora. Fungal Genet Biol 48: 388-399, 2011.

103. Loros JJ and Dunlap JC. Genetic and molecular analysis of circadian rhythms in Neurospora. Annu Rev Physiol 63: 757794, 2001.

104. Loros JJ and Feldman JF. Loss of temperature compensation of circadian period length in the frq-9 mutant of Neurospora crassa. J Biol Rhythms 1: 187-198, 1986.

105. Malzahn E, Ciprianidis S, Kaldi K, Schafmeier T, and Brunner M. Photoadaptation in Neurospora by competitive interaction of activating and inhibitory LOV domains. Cell 142: 762-772, 2010. 
106. Mehra A, Shi M, Baker CL, Colot HV, Loros JJ, and Dunlap JC. A role for casein kinase 2 in the mechanism underlying circadian temperature compensation. Cell 137: 749-760, 2009.

107. Merrow M, Brunner M, and Roenneberg T. Assignment of circadian function for the Neurospora clock gene frequency. Nature 399: 584-586, 1999.

108. Merrow M, Franchi L, Dragovic Z, Gorl M, Johnson J, Brunner M, Macino G, and Roenneberg T. Circadian regulation of the light input pathway in Neurospora crassa. EMBO J 20: 307-315, 2001.

109. Michan S, Lledias F, Baldwin JD, Natvig DO, and Hansberg W. Regulation and oxidation of two large monofunctional catalases. Free Radic Biol Med 33: 521-532, 2002.

110. Michan S, Lledias F, and Hansberg W. Asexual development is increased in Neurospora crassa cat-3-null mutant strains. Eukaryot Cell 2: 798-808, 2003.

111. Morgan LW, Greene AV, and Bell-Pedersen D. Circadian and light-induced expression of luciferase in Neurospora crassa. Fungal Genet Biol 38: 327-332, 2003.

112. Munkres KD. Genetic coregulation of longevity and antioxienzymes in Neurospora crassa. Free Radic Biol Med 8: 355361, 1990.

113. Munkres KD. Genetical, developmental, and thermal regulation of antioxidant enzymes in Neurospora. Free Radic Biol Med 9: 23-28, 1990.

114. Munkres KD and Furtek CA. Selection of conidial longevity mutants of Neurospora crassa. Mech Ageing Dev 25: 47-62, 1984.

115. Munkres KD, Rana RS, and Goldstein E. Genetically determined conidial longevity is positively correlated with superoxide dismutase, catalase, glutathione peroxidase, cytochrome c peroxidase, and ascorbate free radical reductase activities in Neurospora crassa. Mech Ageing Dev 24: 83-100, 1984.

116. Neill SJ, Desikan R, Clarke A, Hurst RD, and Hancock JT. Hydrogen peroxide and nitric oxide as signalling molecules in plants. J Exp Bot 53: 1237-1247, 2002.

117. Neiss A, Schafmeier T, and Brunner M. Transcriptional regulation and function of the Neurospora clock gene white collar 2 and its isoforms. EMBO Rep 9: 788-794, 2008.

118. Noguchi R, Banno S, Ichikawa R, Fukumori F, Ichiishi A, Kimura M, Yamaguchi I, and Fujimura M. Identification of OS-2 MAP kinase-dependent genes induced in response to osmotic stress, antifungal agent fludioxonil, and heat shock in Neurospora crassa. Fungal Genet Biol 44: 208-218, 2007.

119. O'Neill JS, van Ooijen G, Dixon LE, Troein C, Corellou F, Bouget FY, Reddy AB, and Millar AJ. Circadian rhythms persist without transcription in a eukaryote. Nature 469: 554-558, 2011.

120. Oda K and Hasunuma K. Genetic analysis of signal transduction through light-induced protein phosphorylation in Neurospora crassa perithecia. Mol Gen Genet 256: 593-601, 1997.

121. Omata Y, Lewis JB, Rotenberg S, Lockwood PE, Messer RL, Noda M, Hsu SD, Sano H, and Wataha JC. Intra- and extracellular reactive oxygen species generated by blue light. J Biomed Mater Res A 77: 470-477, 2006.

122. Osiewacz HD. Genes, mitochondria and aging in filamentous fungi. Ageing Res Rev 1: 425-442, 2002.

123. Park G, Servin JA, Turner GE, Altamirano L, Colot HV, Collopy P, Litvinkova L, Li L, Jones CA, Diala FG, Dunlap JC, and Borkovich KA. Global analysis of serine-threonine protein kinase genes in Neurospora crassa. Eukaryot Cell 10: 1553-1564, 2011.

124. Peraza L and Hansberg W. Neurospora crassa catalases, singlet oxygen and cell differentiation. Biol Chem 383: 569575, 2002.

125. Pittendrigh CS, Bruce VG, Rosensweig NS, and Rubin ML. Growth patterns in Neurospora: a biological clock in Neurospora. Nature: 169-170, 1959.

126. Pregueiro AM, Liu Q, Baker CL, Dunlap JC, and Loros JJ. The Neurospora checkpoint kinase 2: a regulatory link between the circadian and cell cycles. Science 313: 644-649, 2006.

127. Querfurth C, Diernfellner AC, Gin E, Malzahn E, Hofer T, and Brunner M. Circadian conformational change of the Neurospora clock protein FREQUENCY triggered by clustered hyperphosphorylation of a basic domain. Mol Cell 43: 713-722, 2011.

128. Ramsdale $M$ and Lakin-Thomas PL. sn-1,2-diacylglycerol levels in the fungus Neurospora crassa display circadian rhythmicity. J Biol Chem 275: 27541-27550, 2000.

129. Rhee SG, Woo HA, Kil IS, and Bae SH. Peroxiredoxin functions as a peroxidase and a regulator and sensor of local peroxides. J Biol Chem 287: 4403-4410, 2012.

130. Rigoulet M, Yoboue ED, and Devin A. Mitochondrial ROS generation and its regulation: mechanisms involved in $\mathrm{H}(2) \mathrm{O}(2)$ signaling. Antioxid Redox Signal 14: 459-468, 2011.

131. Ryan FJ. Selected methods of Neurospora genetics. Methods Med Res: 51-75, 1950.

132. Sancar G, Sancar C, Brugger B, Ha N, Sachsenheimer T, Gin E, Wdowik S, Lohmann I, Wieland F, Hofer T, Diernfellner A, and Brunner M. A global circadian repressor controls antiphasic expression of metabolic genes in Neurospora. Mol Cell 44: 687-697, 2011.

133. Sancar G, Sancar C, and Brunner M. Metabolic compensation of the Neurospora clock by a glucose-dependent feedback of the circadian repressor CSP1 on the core oscillator. Genes Dev 26: 2435-2442, 2012.

134. Sargent ML, Briggs WR, and Woodward DO. Circadian nature of a rhythm expressed by an invertaseless strain of Neurospora crassa. Plant Physiol 41: 1343-1349, 1966.

135. Sargent ML and Kaltenborn SH. Effects of medium composition and carbon dioxide on circadian conidiation in Neurospora. Plant Physiol 50: 171-175, 1972.

136. Schafmeier T, Diernfellner A, Schafer A, Dintsis O, Neiss A, and Brunner M. Circadian activity and abundance rhythms of the Neurospora clock transcription factor WCC associated with rapid nucleo-cytoplasmic shuttling. Genes Dev 22: 3397-3402, 2008.

137. Schafmeier T, Haase A, Kaldi K, Scholz J, Fuchs M, and Brunner M. Transcriptional feedback of Neurospora circadian clock gene by phosphorylation-dependent inactivation of its transcription factor. Cell 122: 235-246, 2005.

138. Schafmeier T, Kaldi K, Diernfellner A, Mohr C, and Brunner M. Phosphorylation-dependent maturation of Neurospora circadian clock protein from a nuclear repressor toward a cytoplasmic activator. Genes Dev 20: 297-306, 2006.

139. Scheer FA, Hilton MF, Mantzoros CS, and Shea SA. Adverse metabolic and cardiovascular consequences of circadian misalignment. Proc Natl Acad Sci U S A 106: 44534458, 2009.

140. Schliebs W, Wurtz C, Kunau WH, Veenhuis M, and Rottensteiner H. A eukaryote without catalase-containing microbodies: Neurospora crassa exhibits a unique cellular distribution of its four catalases. Eukaryot Cell 5: 1490-1502, 2006. 
141. Schmoll M, Tian C, Sun J, Tisch D, and Glass NL. Unravelling the molecular basis for light modulated cellulase gene expression - the role of photoreceptors in Neurospora crassa. BMC Genomics 13: 127, 2012.

142. Schneider K, Perrino S, Oelhafen K, Li S, Zatsepin A, LakinThomas $\mathrm{P}$, and Brody S. Rhythmic conidiation in constant light in vivid mutants of Neurospora crassa. Genetics 181: 917-931, 2009.

143. Schwerdtfeger $C$ and Linden $H$. Blue light adaptation and desensitization of light signal transduction in Neurospora crassa. Mol Microbiol 39: 1080-1087, 2001.

144. Schwerdtfeger $\mathrm{C}$ and Linden H. VIVID is a flavoprotein and serves as a fungal blue light photoreceptor for photoadaptation. EMBO J 22: 4846-4855, 2003.

145. Scott B and Eaton CJ. Role of reactive oxygen species in fungal cellular differentiations. Curr Opin Microbiol 11: 488493, 2008.

146. Shrode LB, Lewis ZA, White LD, Bell-Pedersen D, and Ebbole DJ. vvd is required for light adaptation of conidiation-specific genes of Neurospora crassa, but not circadian conidiation. Fungal Genet Biol 32: 169-181, 2001.

147. Sigler K, Chaloupka J, Brozmanova J, Stadler N, and Hofer M. Oxidative stress in microorganisms-I. Microbial vs. higher cells-damage and defenses in relation to cell aging and death. Folia Microbiol (Praha) 44: 587-624, 1999.

148. Smith KM, Sancar G, Dekhang R, Sullivan CM, Li S, Tag AG, Sancar C, Bredeweg EL, Priest HD, McCormick RF, Thomas TL, Carrington JC, Stajich JE, Bell-Pedersen D, Brunner M, and Freitag M. Transcription factors in light and circadian clock signaling networks revealed by genomewide mapping of direct targets for Neurospora white collar complex. Eukaryot Cell 9: 1549-1556, 2010.

149. Sohal RS and Orr WC. The redox stress hypothesis of aging. Free Radic Biol Med 52: 539-555, 2012.

150. Sohyun Park KL. Inverted race tube assay for circadian clock studies of the Neurospora accessions. Fungal Genet Newsl 51: 3, 2004.

151. Springer ML. Genetic control of fungal differentiation: the three sporulation pathways of Neurospora crassa. Bioessays 15: 365-374, 1993.

152. Stadler DR. Growth patterns in Neurospora: genetic control of a cyclic growth pattern in Neurospora. Nature 184: 170$171,1959$.

153. Sun J and Glass NL. Identification of the CRE-1 cellulolytic regulon in Neurospora crassa. PLoS One 6: e25654, 2011.

154. Sun X, Yu L, Lan N, Wei S, Yu Y, Zhang H, Zhang X, and $\mathrm{Li} \mathrm{S}$. Analysis of the role of transcription factor VAD-5 in conidiation of Neurospora crassa. Fungal Genet Biol 49: 379387, 2012.

155. Takahama U, Shimizu-Takahama M, and Egashira T. Reduction of exogenous cytochrome c by Neurospora crassa conidia: effects of superoxide dismutase and blue light. J Bacteriol 152: 151-156, 1982.

156. Takahashi M, Yamashita K, Shiozawa A, Ichiishi A, Fukumori F, and Fujimura M. An AP-1-like transcription factor, NAP-1, regulates expression of the glutathione S-transferase and NADH:flavin oxidoreductase genes in Neurospora crassa. Biosci Biotechnol Biochem 74: 746-752, 2010.

157. Takemoto D, Tanaka A, and Scott B. NADPH oxidases in fungi: diverse roles of reactive oxygen species in fungal cellular differentiation. Fungal Genet Biol 44: 1065-1076, 2007.

158. Talora C, Franchi L, Linden H, Ballario P, and Macino G. Role of a white collar-1-white collar-2 complex in blue-light signal transduction. EMBO J 18: 4961-4968, 1999.
159. Tan Y, Dragovic Z, Roenneberg T, and Merrow M. Entrainment dissociates transcription and translation of a circadian clock gene in Neurospora. Curr Biol 14: 433-438, 2004.

160. Tian C, Kasuga T, Sachs MS, and Glass NL. Transcriptional profiling of cross pathway control in Neurospora crassa and comparative analysis of the Gcn 4 and CPC1 regulons. Eukaryot Cell 6: 1018-1029, 2007.

161. Tian C, Li J, and Glass NL. Exploring the bZIP transcription factor regulatory network in Neurospora crassa. Microbiology 157: 747-759, 2011.

162. Toledo I, Aguirre J, and Hansberg W. Aerial growth in Neurospora crassa: characterization of an experimental model system. Exp Mycol 10: 114-125, 1986.

163. Toledo I, Aguirre J, and Hansberg W. Enzyme inactivation related to a hyperoxidant state during conidiation of Neurospora crassa. Microbiology 140 (Pt 9): 2391-2397, 1994.

164. Toledo I and Hansberg W. Protein oxidation related to morphogenesis in Neurospora crassa. Exp Mycol 14: 184-189, 1990.

165. Toledo I, Noronha-Dutra AA, and Hansberg W. Loss of NAD(P)-reducing power and glutathione disulfide excretion at the start of induction of aerial growth in Neurospora crassa. J Bacteriol 173: 3243-3249, 1991.

166. Toledo I, Rangel P, and Hansberg W. Redox imbalance at the start of each morphogenetic step of Neurospora crassa conidiation. Arch Biochem Biophys 319: 519-524, 1995.

167. Vachali P, Bhosale P, and Bernstein PS. Microbial carotenoids. Methods Mol Biol 898: 41-59, 2012.

168. Vitalini MW, de Paula RM, Goldsmith CS, Jones CA, Borkovich KA, and Bell-Pedersen D. Circadian rhythmicity mediated by temporal regulation of the activity of p38 MAPK. Proc Natl Acad Sci U S A 104: 18223-18228, 2007.

169. Vitalini MW, Morgan LW, March IJ, and Bell-Pedersen D. A genetic selection for circadian output pathway mutations in Neurospora crassa. Genetics 167: 119-129, 2004.

170. Wang N, Yoshida Y, and Hasunuma K. Catalase-1 (CAT-1) and nucleoside diphosphate kinase-1 (NDK-1) play an important role in protecting conidial viability under light stress in Neurospora crassa. Mol Genet Genomics 278: 235-242, 2007.

171. Watters MK, Boersma M, Johnson M, Reyes C, Westrick E, and Lindamood E. A screen for Neurospora knockout mutants displaying growth rate dependent branch density. Fungal Biol 115: 296-301, 2011.

172. Wood ZA, Schroder E, Robin Harris J, and Poole LB. Structure, mechanism and regulation of peroxiredoxins. Trends Biochem Sci 28: 32-40, 2003.

173. Yamashita K, Shiozawa A, Banno S, Fukumori F, Ichiishi A, Kimura M, and Fujimura M. Involvement of OS-2 MAP kinase in regulation of the large-subunit catalases CAT-1 and CAT-3 in Neurospora crassa. Genes Genet Syst 82: 301310, 2007.

174. Yamashita K, Shiozawa A, Watanabe S, Fukumori F, Kimura M, and Fujimura M. ATF-1 transcription factor regulates the expression of ccg- 1 and cat-1 genes in response to fludioxonil under OS-2 MAP kinase in Neurospora crassa. Fungal Genet Biol 45: 1562-1569, 2008.

175. Yang $\mathrm{Q}$ and Borkovich KA. Mutational activation of a Galphai causes uncontrolled proliferation of aerial hyphae and increased sensitivity to heat and oxidative stress in Neurospora crassa. Genetics 151: 107-117, 1999. 
176. Yang Y, Cheng P, and Liu Y. Regulation of the Neurospora circadian clock by casein kinase II. Genes Dev 16: 994-1006, 2002.

177. Yang Y, Cheng P, Zhi G, and Liu Y. Identification of a calcium/calmodulin-dependent protein kinase that phosphorylates the Neurospora circadian clock protein FREQUENCY. J Biol Chem 276: 41064-41072, 2001.

178. Yang Y, He Q, Cheng P, Wrage P, Yarden O, and Liu Y. Distinct roles for PP1 and PP2A in the Neurospora circadian clock. Genes Dev 18: 255-260, 2004.

179. Yoshida $Y$ and Hasunuma K. Reactive oxygen species affect photomorphogenesis in Neurospora crassa. J Biol Chem 279: 6986-6993, 2004.

180. Yoshida $\mathrm{Y}$, Iigusa H, Wang N, and Hasunuma K. Crosstalk between the cellular redox state and the circadian system in Neurospora. PLoS One 6: e28227, 2011.

181. Yoshida Y, Maeda T, Lee B, and Hasunuma K. Conidiation rhythm and light entrainment in superoxide dismutase mutant in Neurospora crassa. Mol Genet Genomics 279: 193202, 2008.

182. Yoshida Y, Ogura Y, and Hasunuma K. Interaction of nucleoside diphosphate kinase and catalases for stress and light responses in Neurospora crassa. FEBS Lett 580: 32823286, 2006.

183. Zickler D. Observing meiosis in filamentous fungi: Sordaria and Neurospora. Methods Mol Biol 558: 91-114, 2009.

184. Zoltowski BD, Schwerdtfeger C, Widom J, Loros JJ, Bilwes AM, Dunlap JC, and Crane BR. Conformational switching in the fungal light sensor Vivid. Science 316: 1054-1057, 2007.

Address correspondence to: Dr. Krisztina Káldi Department of Physiology Semmelweis University Tüzoltó u. 37-47 Budapest, H-1094 Hungary

E-mail: kaldi.krisztina@med.semmelweis-univ.hu

Date of first submission to ARS Central, July 26, 2013; date of acceptance, August 21, 2013.

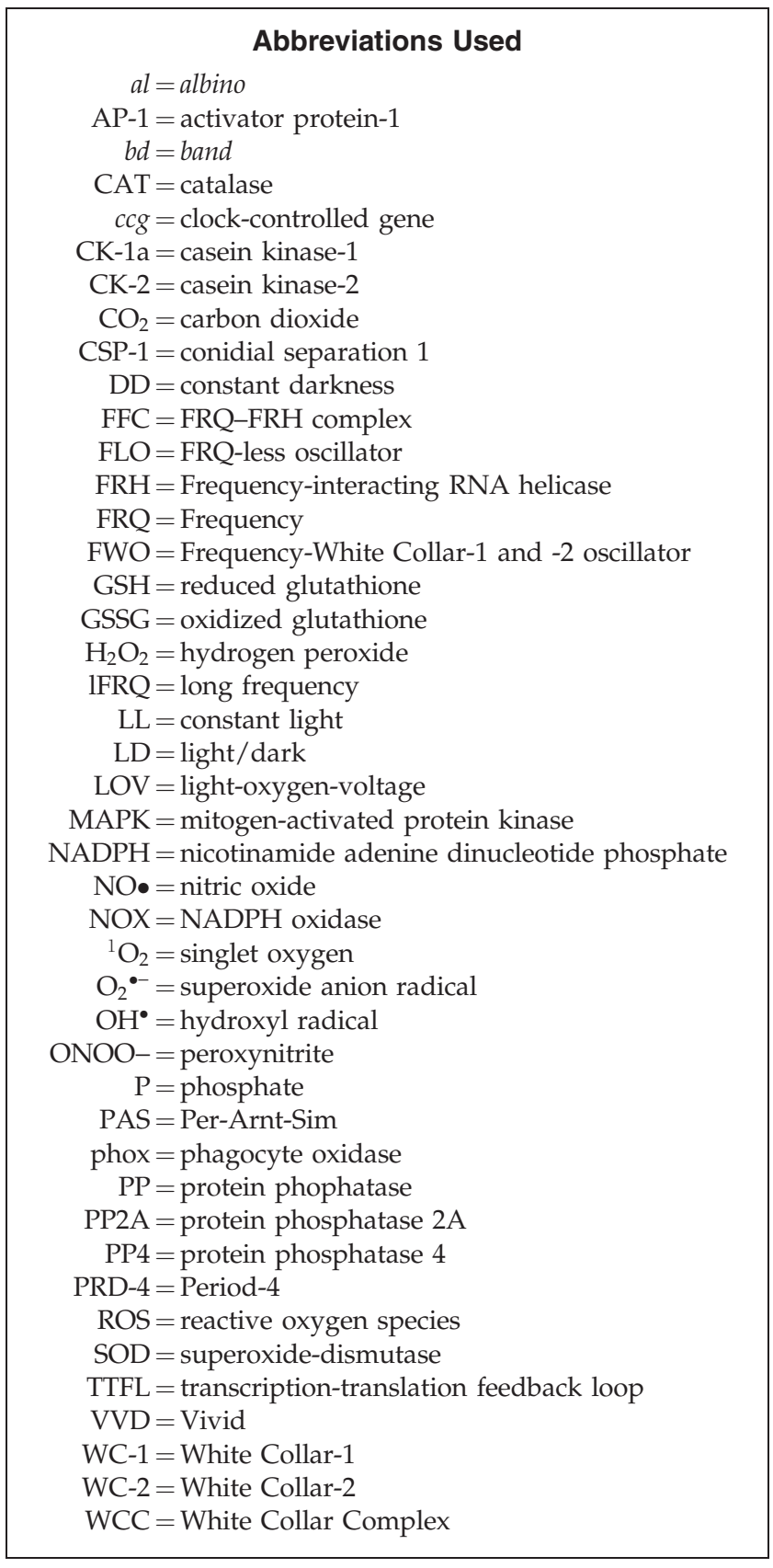

